\title{
Numerical Simulation of Reinforced Concrete Shear Walls Using Force-Based Fiber Element Method
}

\section{MUHAMMET KARATON ( $\nabla$ mkaraton@firat.edu.tr)}

Firat Univ. Engineering Faculty

Ömer Faruk Osmanlı

Fırat Üniversitesi: Firat Universitesi

Mehmet Eren GÜLŞAN

Gaziantep University: Gaziantep Universitesi

\section{Research Article}

Keywords: Shear wall, Fiber element, Force-based, Damping types, Damping ratio and Seismic loads.

Posted Date: March 17th, 2021

DOI: https://doi.org/10.21203/rs.3.rs-296727/v1

License: (c) (1) This work is licensed under a Creative Commons Attribution 4.0 International License. Read Full License 


\title{
Numerical Simulation of Reinforced Concrete Shear Walls Using Force-Based Fiber Element Method
}

\author{
Muhammet Karaton ${ }^{1 a}$, Ömer Faruk Osmanlı ${ }^{1 b}$, Mehmet Eren Gülşan²c \\ ${ }^{1}$ Department of Civil Engineering, Firat University, Elazig, Turkey. \\ ${ }^{2}$ Department of Civil Engineering, Gaziantep University, Gaziantep, Turkey. \\ a e-mail: mkaraton@firat.edu.tr ORCID: 0000-0002-1498-4659 \\ b e-mail: ofosmanli@firat.edu.tr ORCID: 0000-0002-9799-3103 \\ c e-mail: gulsan@gantep.edu.tr ORCID: 0000-0002-8991-0363 \\ Corresponding Author, Email: mkaraton@gantep.edu.tr
}

\begin{abstract}
Reinforced concrete shear walls are the structural elements that considerably increase the seismic performance of buildings. Fiber elements and fiber-spring elements are used for the modeling of the inelastic behavior of these elements. The Fiber Element Method provides a certain amount of accuracy for the modeling of reinforced concrete shear walls. However, the studies related to this method are still in progress.

In this study, the efficiency of the force-based Fiber Element Method is investigated for different damping ratios and different damping types that used in the structural damping for reinforced concrete shear wall structures. Two shear wall structures that subjected to seismic loads are used for the comparison of numerical analysis and experimental results. The comparisons are achieved according to the absolute maximum values of the overturning moment, the base shear force, and the roof displacement. Rayleigh damping and stiffnessproportional damping types for the damping ratios that vary between $2-3 \%$ provide better results than massproportional damping. Additionally, the optimum number of fiber element for Rayleigh and stiffnessproportional damping types is determined for the optimum damping ratio that provides minimum differences between numerical analysis and experimental results. For these damping types, when the length of a fiber is smaller than $3 \%$ of the longitudinal length of the shear wall at the optimum damping ratios, the roof displacement differences between numerical analysis and experimental results are less than $2.5 \%$.
\end{abstract}

Key Words: Shear wall, Fiber element, Force-based, Damping types, Damping ratio and Seismic loads. 


\section{Introduction}

Shear walls are the structural elements that considerably enhance the lateral load capacity of the reinforced concrete (RC) structures subjected to the earthquake. There are many experimental studies to investigate the seismic behavior of these elements in the literature (Peterman et al., 2016; Shen et al., 2017; Huang et al., 2018; Wang et al., 2018; Rong et al., 2020). On the other hand, the numerical simulation of these elements is an essential researching subject for assessing the nonlinear behavior of the structures. RC shear walls are simulated by using several modeling approaches (Dashti et al., 2017; Nikolić et al., 2017; Feng et al., 2018; Zhang et al., 2020). In the most accepted numerical modeling approach, beam-column elements are utilized with nonlinear axial and rotational springs. The springs were positioned in the vertical direction of the wall center. In spite of the modification of beam-column elements conducted by using multiple springs, the model is inadequate for the modeling of shear wall behavior. The inadequacies are resulted from ignoring the interaction between the shear wall with frame elements and the neutral axis variation in wall cross-section. Three-Vertical-Line-Element Model (TVLEM) and Multiple-Vertical-Line-Element Model (MVLEM) were developed depending on the beam-column element model. In these models, the vertical line elements that containing nonlinear springs to be at the top and bottom of the wall are attached to the rigid beams (Orakcal et al. 2004). Based on the MVLEM, a macroscopic fiber model was developed to simulate the nonlinear behavior of the reinforced concrete shear wall using a series of uniaxial elements by Orakcal et al. (2004). In this model, the axial stiffness of the exterior columns is represented with at least two boundary elements. The flexural and axial stiffness of the interior panel are simulated with a minimum of two central elements. The number of uniaxial elements (macro fibers) can be enhanced for a more refined definition of the section.

The distributed plastic hinge model adopted in most design codes is commonly used to model the nonlinear behavior of RC structural elements. In this model, steel reinforcement and concrete portions in the cross-section of each structural element are simulated by fiber elements. The nonlinear response of the structural element is calculated by weighted integration of the behavior of the cross-sections by considering the material nonlinearity. The element deformations and the element forces are determined by convenient interpolation functions in the global element displacement and forces. The strains are assumed to be linearly distributed through the cross-section of the element. Therefore, plane sections are considered to be remain plane during the bending (Taucer et al., 1991). In the model known as Fiber Element Method, the constitutive relation of the cross-sections (integration points) is obtained by using the integration of the behavior of fiber elements. The method that depends on both displacement-based and force-based formulations is used to simulate the nonlinear behavior of RC beam, column, and shear wall elements (Martinelli et al., 2013; Li et al., 2016; Vásquez et al., 2016; Feng and $\mathrm{Xu}, 2018$; $\mathrm{Li}$ et al., 2018). However, there are still uncertainties related to the damping ratio and the damping type for the RC structures, the number of integration points used in an element and the fiber element number used in the section.

In this study, nonlinear time-history analyses of the RC shear wall structures are conducted by using the force-based fiber element (FBFE) method. Two different RC structure that consist of shear walls are simulated under the 1994 Northridge and the 1957 San Francisco earthquake loadings. The optimum damping ratio for the stiffness-proportional damping (SPD), mass-proportional damping (MPD), and Rayleigh damping (RD) are investigated. Besides, the optimum fiber element number is determined for the damping types and optimum damping ratio. The numerical analysis results are compared with experimental results in terms of absolute 
maximum values of the base overturning moment, the base shear force, and the top displacement. Time-history graphs of top displacement responses for the shear wall structures are also used in the comparisons. The nonlinear seismic analyses are performed by using SeismoStruct (Seismosoft, 2016). The reasonable range of the damping ratio for $\mathrm{RC}$ structures with shear walls is determined.

\section{Fiber Element Method}

The Fiber Element Method represented by both displacement-based and force-based formulations depends on the model of the beam-column element. The uniaxial stress-strain response of the longitudinal fibers that constitutive the relation of force-deformation of the section is used in force-based formulations. The method considers the assumption of linear geometry for the plane sections during the deformation. In the method, the nonlinear response of an element is provided by the nonlinearity of fibers stress-strain relation.

In the Fiber Element Method, the structural element is sectioned depending on the integration points (Fig. 1). The number of integration points in an element and the number of fibers (discretization) in a crosssection affect the response of the element, and thereby the response of the structure. Using more fiber elements increases the accuracy of the element behavior as well as increasing the time and effort needed for the computation (Taucer et al., 1991).

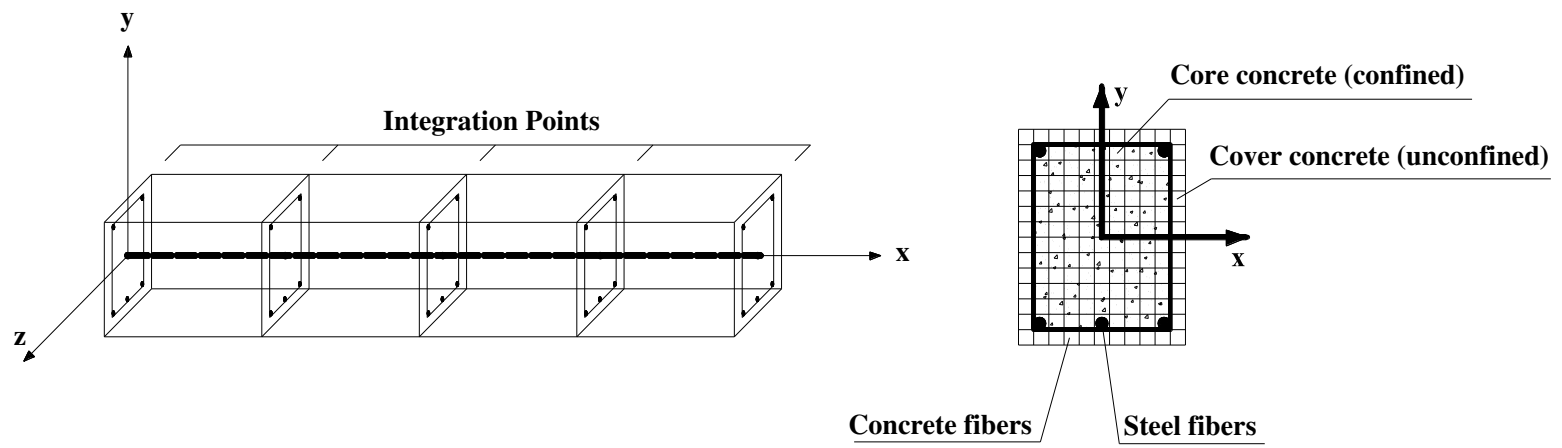

Fig. 1 The fiber beam-column element and discretization of the cross-section (Seismosoft, 2016)

\subsection{The Fiber Element Formulation of Beam-Column Element}

Force-based fiber element formulation of an element depends on the equilibrium and the force-deformation relation of the sections. Therefore, beam-column fiber elements are developed by using deformation interpolation function, $a(x)$ and force interpolation function, $b(x)$. Element flexibility matrix, $\boldsymbol{F}^{i-1}$ and a matrix only depending on the interpolation function matrices, $\boldsymbol{T}$ can be defined in a simpler form as,

$$
\begin{gathered}
\boldsymbol{F}^{i-1}=\left[\int_{0}^{L} b^{T}(x) \cdot f^{i-1}(x) \cdot b(x) \cdot d x\right] \\
\boldsymbol{T}=\left[\int_{0}^{L} b^{T}(x) \cdot a(x) \cdot d x\right]
\end{gathered}
$$

The element deformation field is represented by the flexibility dependent shape functions by using following equations;

$$
a(x)=f^{i-1}(x) \cdot b(x) \cdot\left[\boldsymbol{F}^{i-1}\right]^{-1}
$$


where, $f$ is flexibility matrix of a section. $i$ denotes iteration number of Newton-Raphson iteration loop at the structural level (Taucer et al. 1991). Thus, $f^{i-1}$ denotes that flexibility matrix of a section at $(i-1)^{\text {th }}$ NewtonRaphson iteration. Using the interpolation functions, the relation between the section deformations and the element deformations can be drawn as follows;

$$
\Delta d^{i}(x)=f^{i-1}(x) \cdot b(x) \cdot\left[\boldsymbol{F}^{i-1}\right]^{-1} \Delta q^{i}
$$

where, $\Delta d$ and $\Delta q$ are the incremental section deformation and the incremental element deformation, respectively. $\boldsymbol{T}$ matrix become a $3 \times 3$ identify matrix $\boldsymbol{I}$ by using the special selection of the deformation shape functions. This expression can be proved by the following equation;

$$
\boldsymbol{T}=\left[\int_{0}^{L} b^{T}(x) \cdot a(x) \cdot d x\right]=\left[\int_{0}^{L} b^{T}(x) \cdot \boldsymbol{f}^{i-1}(x) \cdot b(x) \cdot d x\right] \cdot\left[\boldsymbol{F}^{i-1}\right]^{-1}=\boldsymbol{I}
$$

The deformation interpolation function changes during the iterative solution procedure. Therefore, the method proposed in this study is called as FBFE method. The force field is expressed by using section force vector where two bending moments $\left(M_{z}(x)\right.$ and $\left.M_{y}(x)\right)$ are linear and axial force $(N(x))$ is constant (Taucer et al., 1991). Thus, force interpolation function is obtained by result of this expression in a matrix form as;

$$
b(x)=\left[\begin{array}{ccccc}
\left(\frac{x}{L}-1\right) & \left(\frac{x}{L}\right) & 0 & 0 & 0 \\
0 & 0 & \left(\frac{x}{L}-1\right) & \left(\frac{x}{L}\right) & 0 \\
0 & 0 & 0 & 0 & 1
\end{array}\right]
$$

The force interpolation function, $b(x)$ provides the relation between force distributions along the element with element force vector by using following equation.

$$
\Delta \mathbf{D}^{i}(x)=b(x) \cdot \Delta \mathbf{Q}^{i}
$$

where, $\Delta \mathbf{D}(x)$ and $\Delta \mathbf{Q}$ are incremental section force vector and incremental element force vector, respectively. The increments of the fiber strain $\Delta \mathbf{e}^{j}(x)$ are

$$
\Delta \mathbf{e}^{j}(x)=I(x) \cdot \Delta \mathbf{d}^{j}(x)
$$

where, subscript $j$ is the iteration number at the element level, $\Delta \mathbf{d}^{j}(x)$ is the given deformation increments and $\mathbf{I}(x)$ is the section compatibility matrix that can be defined as;

$$
\mathbf{I}(x)=\left[\begin{array}{ccc}
-y_{1} & z_{1} & 1 \\
\mathrm{M} & \mathrm{M} & \mathrm{M} \\
-y_{i f i b} & z_{i f i b} & 1 \\
\mathrm{M} & \mathrm{M} & \mathrm{M} \\
-y_{n} & z_{n} & 1
\end{array}\right]
$$

In this equation, $x$ denotes the location of the integration section along the element longitudinal axis, $y_{i f i b}$ and $z_{i f i b}$ denote the location of the fiber in the section. Considering the fiber strain increments, the new tangent 
modulus $E_{i f i b}^{j}$ and stress $\sigma_{i f i b}^{j}$ of all fibers are calculated by using the suitable stress-strain relation of fiber. The new tangent stiffness matrix of the section $\mathbf{k}^{j}(x)$ is determined as follows,

$$
\mathbf{k}^{j}(x)=\mathbf{I}^{T}(x) \cdot\left(\mathbf{E}_{\tan }^{j} \mathbf{A}\right) \cdot \mathbf{I}(x)
$$

where, $\mathbf{E}_{\mathrm{tan}}^{j}$ is the tangent modulus that consists of fiber stresses in diagonal matrix form and $\mathbf{A}$ is the diagonal matrix form of the fiber areas $A_{i f i b}$. The new tangent stiffness matrix of the section is can be also stated as,

$$
\mathbf{k}^{j}(x)=\left[\begin{array}{ccc}
\sum_{i f i b=1}^{n(x)} E_{i f i b}^{j} \cdot A_{i f i b} \cdot y_{i f i b}^{2} & \sum_{i f i b=1}^{n(x)} E_{i f i b}^{j} \cdot A_{i f i b} \cdot y_{i f i b} \cdot z_{i f i b} & -\sum_{i f i b=1}^{n(x)} E_{i f i b}^{j} \cdot A_{i f i b} \cdot y_{i f i b} \\
\sum_{i f i b=1}^{n(x)} E_{i f i b}^{j} \cdot A_{i f i b} \cdot y_{i f i b} \cdot z_{i f i b} & \sum_{i f i b=1}^{n(x)} E_{i f i b}^{j} \cdot A_{i f i b} \cdot z_{i f i b}^{2} & \sum_{i f i b=1}^{n(x)} E_{i f i b}^{j} \cdot A_{i f i b} \cdot z_{i f i b} \\
-\sum_{i f i b=1}^{n(x)} E_{i f i b}^{j} \cdot A_{i f i b} \cdot y_{i f i b} & \sum_{i f i b=1}^{n(x)} E_{i f i b}^{j} \cdot A_{i f i b} \cdot z_{i f i b} & \sum_{i f i b=1}^{n(x)} E_{i f i b}^{j} \cdot A_{i f i b}
\end{array}\right]
$$

The new tangent flexibility matrix of the section $f^{j}(x)$ is obtained by the inverted form of the new tangent stiffness matrix for the section (Taucer et al., 1991; Martinelli, 2007; Karaton, 2014). In the similar manner, the section resisting forces $D_{R}^{j}(x)$ is determined by the following matrix equation:

$$
\boldsymbol{D}_{\boldsymbol{R}}^{j}(x)=\left\{\begin{array}{c}
-\sum_{i f i b=1}^{n(x)} \sigma_{i f i b}^{j} \cdot A_{i f i b} \cdot y_{i f i b} \\
\sum_{i f i b=1}^{n(x)} \sigma_{i f i b}^{j} \cdot A_{i f i b} \cdot z_{i f i b} \\
\sum_{i f i b=1}^{n(x)} \sigma_{i f i b}^{j} \cdot A_{i f i b}
\end{array}\right\}
$$

The numerical results are affected by the material models defined for the nonlinear behavior of the steel and concrete fibers in the sections. In this study, the simulation of the nonlinear response of the reinforcement is achieved by the modified Menegotto and Pinto steel model (Menegotto and Pinto, 1973). Mander-Priestley-Park model (Menegotto and Pinto, 1973) is selected for the material model of the concrete (Fig. 2).

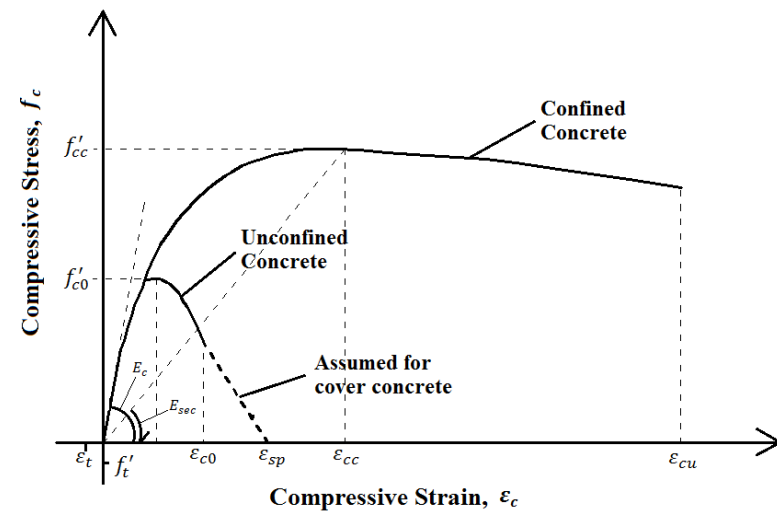

a)

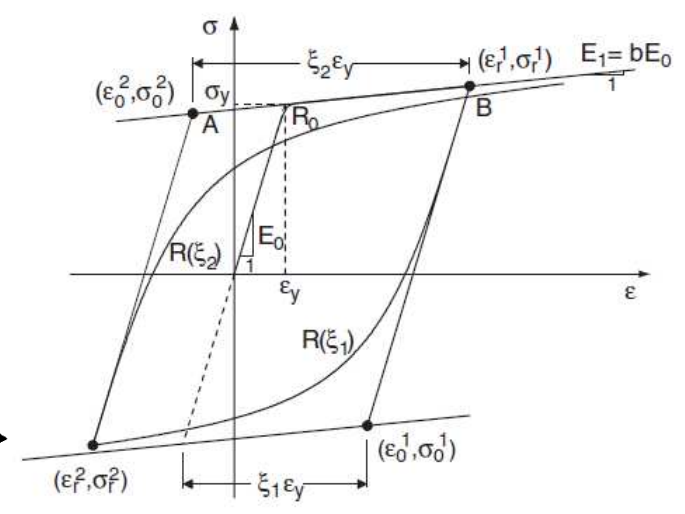

b)

Fig. 2 a) Mander-Priestley-Park concrete model (Mander et al., 1988) and b) Modified Menegotto and Pinto steel model (Kolozvari et al., 2015). 


\section{Numerical Investigation}

The numerical simulations of CAMUS I and NEES-UCSD RC shear wall structures were investigated with the FBFE method. The experimental results obtained by previous shaking table tests of these shear wall structures were compared with nonlinear seismic analysis results. For the seismic input, the 1957 San Francisco and the 1994 Northridge earthquake loadings, same as the experimental study are used for the CAMUS I structure and NEEDS-UCSD structure, respectively (Kazaz et al., 2006; Martinelli, 2007; Martinelli and Filippou, 2009). Seismostruct software was utilized in the nonlinear time-history analyses of the RC shear wall structures by including geometric nonlinearity. In the software, the computation of the nonlinear response of element crosssections is achieved by the FBFE method while the global solutions of the structural element are carried out by the Finite Element Method.

\subsection{The structural damping}

In this study, the equations of motion for the building are solved by using the Hilber-Hughes-Taylor- $\alpha$ (HHT- $\alpha$ ) integration method. Compact form of the equation of motion for the building is given according to HHT- $\alpha$ method as,

$$
[M]\{a\}_{i+1}+(1+\alpha)[C]_{i+1}\{v\}_{i+1}-\alpha[C]_{i}\{v\}_{i}+(1+\alpha)\{F\}_{i+1}-\alpha\{F\}_{i+1}=(1+\alpha)\left\{F_{g}\right\}_{n+1}-\alpha\left\{F_{g}\right\}_{n}
$$

where $\{u\},\{v\}$, and $\{a\}$ denote the relative displacement, velocity, and acceleration for the structure, respectively. Subscript $i$ shows nonlinear solution step and $n$ shows the external load step; $\{F\}$ indicates the internal load vector; $\left\{F_{g}\right\}$ indicates the external load that formed because of ground acceleration vectors. $\alpha$ is a constant to control the numerical dissipation. $[C]$ and $[M]$ show damping matrix and mass matrix of the structure. Damping matrix represents structural damping in numerical analysis. The matrix is obtained by stiffness matrix $([K])$ and the mass matrix as,

$$
[C]_{i}=\alpha_{c} \cdot[M]+\beta_{C} \cdot[K]_{i}
$$

where, $\beta_{c}$ and $\alpha_{c}$ are coefficients for the stiffness matrix and the mass matrix, respectively (Calayir and Karaton, 2005).

The damping ratio varies between $1 \%$ and $10 \%$ in a typical RC structure except for the special cases (Celep and Kumbasar, 2004). The damping ratio is generally assumed as 5\% in numerical analyses of the structures. In most of the building codes, seismic design spectra are defined with respect to $5 \%$ damping ratio. However, based on the findings of Fritz et al. (2009), it was also recommended that the damping ratio can be selected as 3\% in the numerical analysis of the RC shear walls subjected to earthquake loading in all vibration modes (Gilles and McClure, 2012). The dynamic properties of 27 different RC shear wall structures were obtained in accordance with the ambient vibration test results. The mean of the damping ratios that vary between $1 \%$ and $4 \%$ was computed as $2 \%$. It was also concluded that the critical range of the damping ratio was $3 \%-4 \%$ (Gilles and McClure, 2012).

In this study, properly using the damping ratio and the damping type in the numerical analyses of the RC shear wall structures are investigated for the FBFE method. The SPD, MPD, and RD types for structural damping are selected and the damping ratio is changed between $2 \%$ and $5 \%$. 


\subsection{Numerical Analysis of the CAMUS I Shear Wall}

The shaking table test of the CAMUS I shear wall structure was conducted at Azalée (France). The structure scaled by $1 / 3$ includes two parallel shear walls $(0.06 \times 1.7 \mathrm{~m}$ dimensions in cross-section) that connected with rigid diaphragms ( $1.7 \times 1.7 \mathrm{~m}$ dimensions in cross-section). CAMUS I consists of 5 floors with a height of $0.9 \mathrm{~m}$ and a footing with a height of $0.6 \mathrm{~m}$. Steel reinforcement and mass details for one shear wall of the structure are shown in Fig.3. $5 \mathrm{~mm}$ steel reinforcements with $170 \mathrm{~mm}$ spacing were selected for stirrups in the numerical simulation. The tensile strength of steel reinforcement was taken as $500 \mathrm{MPa}$. The elasticity modulus and the compressive strength of the concrete were obtained from the experimental results as $35 \mathrm{MPa}$ and $28000 \mathrm{MPa}$, respectively. (Martinelli, 2007). The tensile strength of the concrete $f_{t}$ was computed as $3.291 \mathrm{MPa}$ by applying the following equation,

$$
f_{t}=0.5563 \sqrt{f_{c k}}
$$

where, $f_{c k}$ denotes the uniaxial compressive strength of the concrete (ACI 318-02, 1999). The units are MPa in Eq. (15).

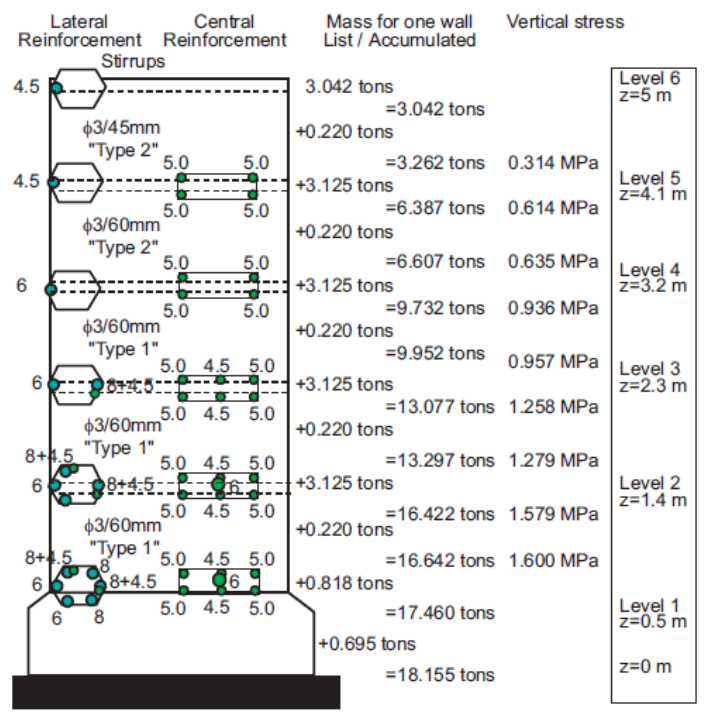

Fig. 3 Steel reinforcement and mass details for one wall of the CAMUS I structure (Martinelli, 2007)

The CAMUS I structure was subjected to third earthquake loading of 1957 San Francisco earthquake in the experimental study. The Peak Ground Acceleration (PGA) value of the inputted ground motion was 1.11g. Since the structure was scaled, the acceleration time-history graph applied to the structure was also scaled by a factor of 2 for the acceleration axis and $1 / \sqrt{3}$ for the time axis as seen in Fig. 4 (Kazaz et al., 2006). The absolute maximum base overturning moment, base shear force, and top displacement were obtained as 324 $\mathrm{kN} \cdot \mathrm{m}, 112 \mathrm{kN}$, and $13.20 \mathrm{~mm}$, respectively.

The finite element model that consists of 14 nodes and 12 elements of the CAMUS I structure is seen in Fig. 5. In the numerical solutions obtained with the FBFE method, 4 constant integration points were considered in one element. Additionally, the number of fiber elements used in a cross-section was variated to observe the effect of the method. The maximum number of iteration was selected as 50 for the global solution as 300 for the element solutions. 


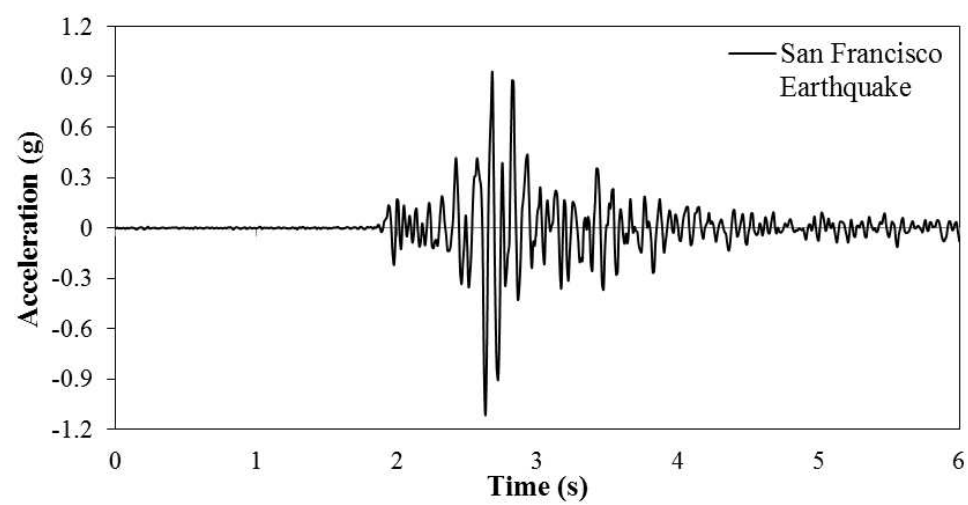

Fig. 4 The scaled 1957 San Francisco earthquake loading (Kazaz et al., 2006)

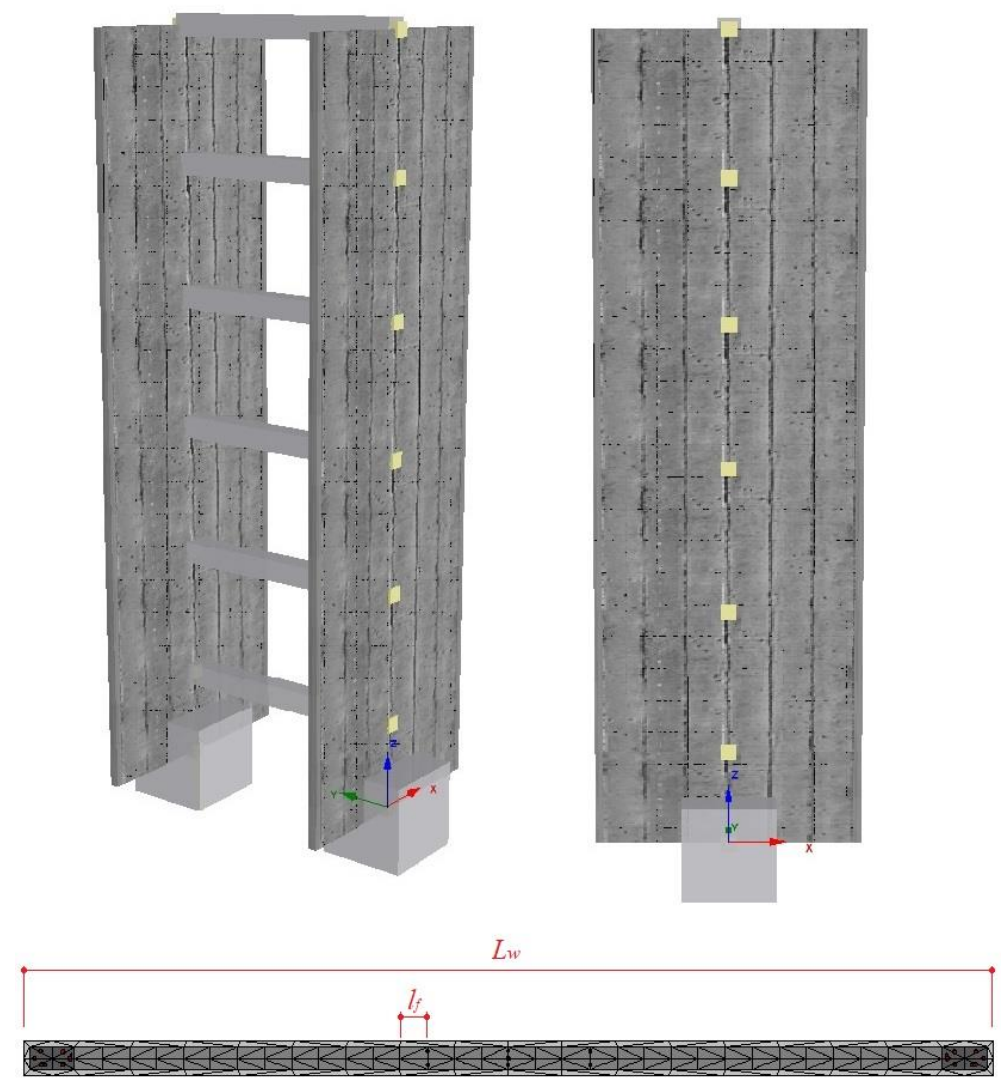

Fig. 5 3D view of the CAMUS I structure model and meshing of the shear wall

Results of experimental and numerical analysis were compared according to maximum absolute overturning moment, base shear force, and top displacement values. The time-history graphs of the top displacement responses are also examined for comparisons. The fiber element number, the damping type, and damping ratio were considered as variable parameters. The number of fiber elements was 250 for the first solution phase. This value was changed in order to observe the efficiency of the FBFE method on the seismic behavior of RC shear wall structures. The sectional properties of the shear wall and meshing of the fiber elements are illustrated in Fig. 5. The mean length of fiber elements and the longitudinal length of the shear wall are symbolized by $l_{f}$ and $L_{w}$ (Fig. 5), respectively. 
Table 1 Eigenvalue analysis results of the CAMUS I

\begin{tabular}{cccccccc}
\hline Mode & Period & $\mathbf{U}_{\mathbf{x}}(\boldsymbol{\%})$ & $\mathbf{U}_{\mathbf{y}}(\boldsymbol{\%})$ & $\mathbf{U}_{\mathbf{z}}(\boldsymbol{\%})$ & $\mathbf{R}_{\mathbf{x}}(\boldsymbol{\%})$ & $\mathbf{R}_{\mathbf{y}}(\boldsymbol{\%})$ & $\mathbf{R}_{\mathbf{z}}(\boldsymbol{\%})$ \\
\hline $\mathbf{1}$ & $\mathbf{0 . 8 2 4 0 1 4}$ & 0.00 & $\mathbf{6 4 . 0 1}$ & 0.00 & 34.21 & 0.00 & 0.00 \\
$\mathbf{2}$ & 0.136323 & 0.00 & 19.72 & 0.00 & 14.93 & 0.00 & 0.00 \\
$\mathbf{3}$ & $\mathbf{0 . 1 2 1 1 0 7}$ & $\mathbf{7 0 . 4 5}$ & 0.00 & 0.00 & 0.00 & 1088.45 & 0.00 \\
$\mathbf{4}$ & 0.119675 & 0.00 & 0.00 & 0.00 & 0.00 & 0.00 & 1028.37 \\
$\mathbf{5}$ & 0.090578 & 0.00 & 0.10 & 0.00 & 0.18 & 0.00 & 0.00 \\
$\mathbf{6}$ & 0.049915 & 0.00 & 6.49 & 0.00 & 8.16 & 0.00 & 0.00 \\
$\mathbf{7}$ & 0.026083 & 0.00 & 3.34 & 0.00 & 5.12 & 0.00 & 0.00 \\
$\mathbf{8}$ & 0.022528 & 0.00 & 3.11 & 1.63 & 5.06 & 0.00 & 0.00 \\
$\mathbf{9}$ & 0.019420 & 19.88 & 0.00 & 0.00 & 0.00 & 254.70 & 0.00 \\
$\mathbf{1 0}$ & 0.019389 & 0.00 & 0.00 & 0.00 & 0.00 & 0.00 & 288.92 \\
$\mathbf{1 1}$ & 0.006804 & 5.08 & 0.00 & 0.00 & 0.00 & 114.07 & 0.00 \\
$\mathbf{1 2}$ & 0.005995 & 0.00 & 0.05 & 84.08 & 0.09 & 0.00 & 0.00 \\
$\mathbf{1 3}$ & 0.003387 & 1.58 & 0.00 & 0.00 & 0.00 & 43.54 & 0.00 \\
$\mathbf{1 4}$ & 0.003310 & 0.00 & 5.01 & 0.05 & 8.90 & 0.00 & 0.40 \\
$\mathbf{1 5}$ & 0.002081 & 0.42 & 0.00 & 0.00 & 0.00 & 12.92 & 0.00 \\
$\mathbf{1 6}$ & 0.000969 & 2.59 & 0.00 & 0.00 & 0.00 & 89.81 & 0.00 \\
\hline The bold values show the maximum mass participation ratio and the related periods. & & & &
\end{tabular}

Eigenvalue analysis was achieved in order to determine the natural frequency of the shear wall. Effective modal mass percentages are shown in Table 1 . In this table, $U_{x}, U_{y}$ and $U_{z}$ represent the displacements in the $x, y$ and $z$ directions, respectively. $\mathrm{R}_{\mathrm{x}}, \mathrm{R}_{\mathrm{y}}$ and $\mathrm{R}_{\mathrm{z}}$ are the rotations around $x, y$ and $z$ axes, respectively. As seen in Table 1, mode 3 has the highest mass participation ratio. Natural frequency of mode 3 was selected for the SPD and MPD computations. However, the natural frequency of mode 1 that has the second highest value, was also used for the RD computation.

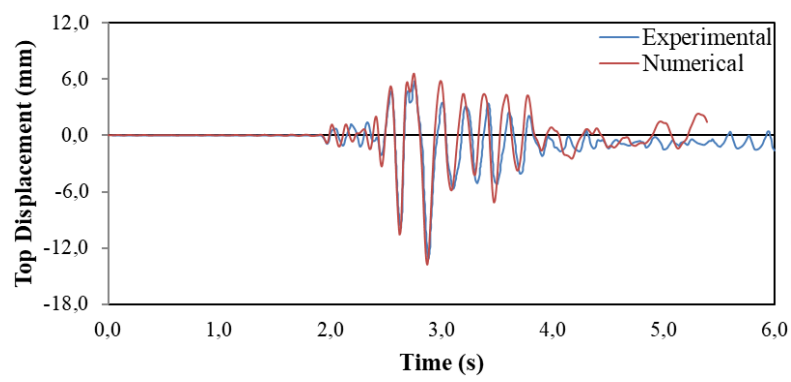

a) SPD

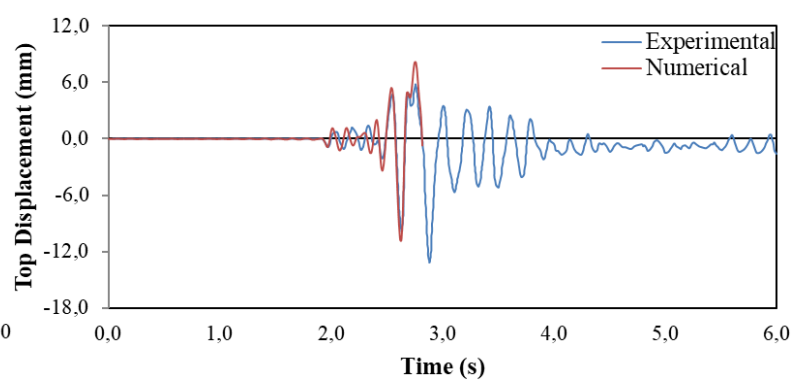

b) MPD

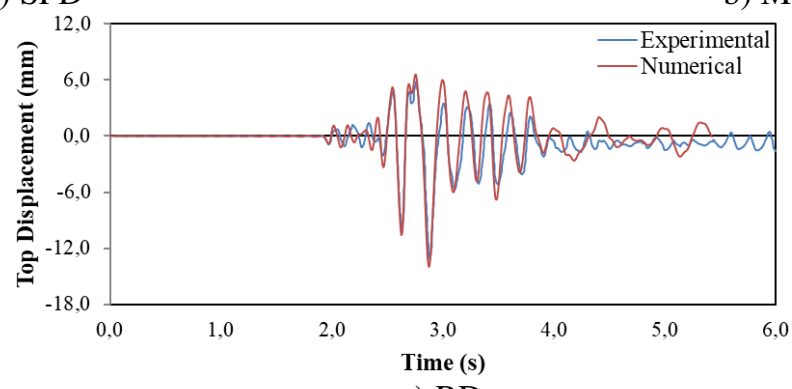

c) RD

Fig. 6 Top displacement responses of the CAMUS I for the damping ratio of $2 \%$

Roof displacement time-history graphs obtained from numerical analysis results of the CAMUS I structure were acquired at the 2\%,3\%, and 5\% damping ratios using the San Francisco earthquake loading. Comparisons of experimental and numerical results were given in Figs. 6-8. Numerical solutions for SPD, MPD and $\mathrm{RD}$ with $2 \%$ damping ratio was converged until $\mathrm{t}=5.38 \mathrm{sec}$., $\mathrm{t}=2.81 \mathrm{sec}$. and $\mathrm{t}=5.41$ sec., respectively. Although solution for MPD cannot be obtained after $\mathrm{t}=4.33 \mathrm{sec}$., solutions for SPD and RD were completed for 
$3 \%$ damping ratio. Solutions for SPD and MPD at 5\% damping ratio was not converged at $\mathrm{t}=4.84$ sec., $\mathrm{t}=2.72$ sec., respectively. In this damping ratio, only numerical solution with RD was completed for all earthquakeloading steps.

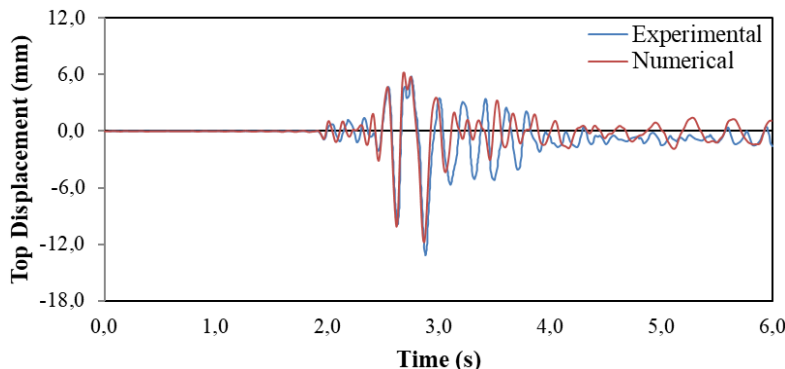

a) SPD

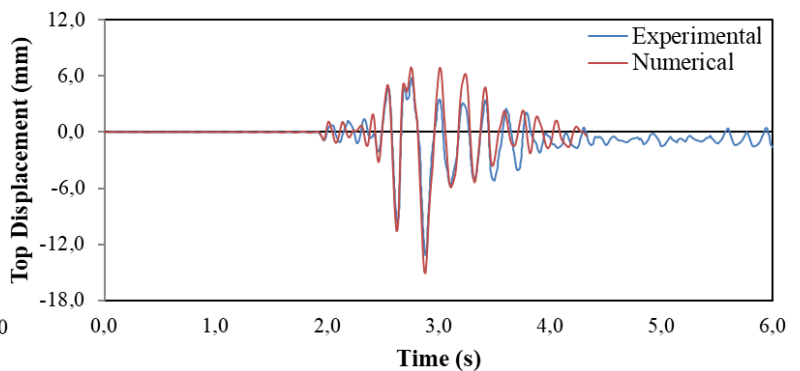

b) MPD

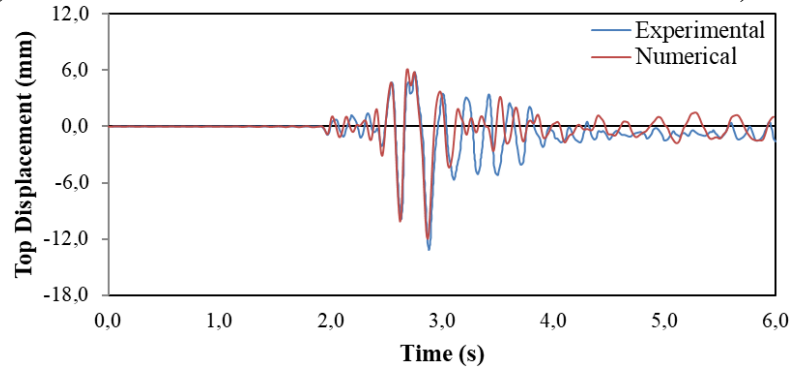

c) $\mathrm{RD}$

Fig. 7 Top displacement responses of the CAMUS I for the damping ratio of $3 \%$

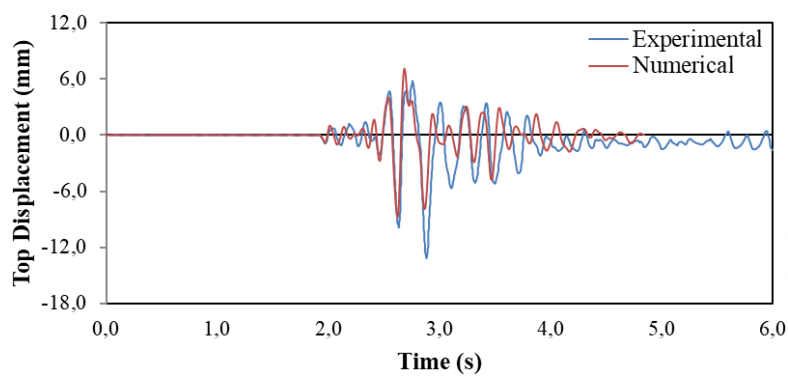

a) SPD

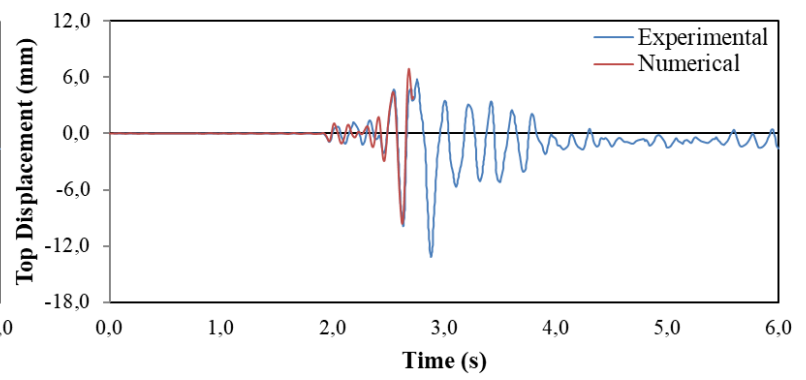

b) MPD

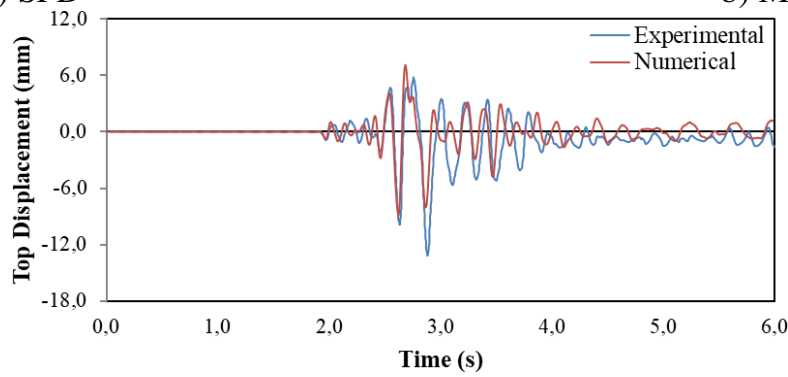

c) $\mathrm{RD}$

Fig. 8 Top displacement responses of the CAMUS I for the damping ratio of 5\%

Experimental and numerical results are compared in Table 2 for damping ratios changing between 2$5 \%$, and for three damping types. In this table, the least differences of the absolute maximum top displacement values between numerical and experimental analysis for SPD, MPD, and RD types were defined as $0.21 \%$ at $2.5 \%$ damping ratio, $0.85 \%$ at $4.5 \%$ damping ratio, and $3.16 \%$ at $2.5 \%$ damping ratio, respectively. The minimum differences of the absolute maximum base shear force values between numerical and experimental 
analysis for SPD, MPD, and RD types were obtained as $0.27 \%$ at $2 \%$ damping ratio, $2.86 \%$ at $5.0 \%$ damping ratio, and $0.84 \%$ at $4.5 \%$ damping ratio, respectively. Additionally, the minimum differences of the absolute maximum base overturning moment values between numerical and experimental analysis results for SPD, MPD, and RD types were obtained as $7.28 \%, 1.93 \%$ and $7.68 \%$ at $2.5 \%$ damping ratio, respectively.

Table 2 The absolute maximum values obtained by numerical analyses and the comparison with experimental results of the CAMUS I structure for the damping ratios that vary between $2 \%$ and $5 \%$

\begin{tabular}{|c|c|c|c|c|c|c|c|}
\hline Da & ping & Top Dis| & acement & Base Sh & Ir Force & Overturn & g Moment \\
\hline $\begin{array}{l}\text { Damping } \\
\text { Type }\end{array}$ & $\begin{array}{c}\text { Damping } \\
\text { Ratio } \\
(\%)\end{array}$ & $\begin{array}{c}\text { Absolute } \\
\text { maximum } \\
(\mathbf{m m})\end{array}$ & $\begin{array}{c}\text { Difference } \\
\text { between } \\
\text { Exp. and } \\
\text { Num. } \\
\text { Analysis } \\
(\%)\end{array}$ & $\begin{array}{c}\text { Absolute } \\
\text { maximum } \\
(\mathbf{k N})\end{array}$ & $\begin{array}{c}\text { Difference } \\
\text { between } \\
\text { Exp. and } \\
\text { Num. } \\
\text { Analysis } \\
(\%)\end{array}$ & $\begin{array}{c}\text { Absolute } \\
\text { maximum } \\
\text { (kN.m) }\end{array}$ & $\begin{array}{c}\text { Difference } \\
\text { between } \\
\text { Exp. and } \\
\text { Num. } \\
\text { Analysis } \\
(\%)\end{array}$ \\
\hline & 2.0 & 13.78 & 4.42 & 111.69 & 0.27 & 299.61 & 7.53 \\
\hline & 2.5 & 13.17 & 0.21 & 107.60 & 3.93 & 300.41 & 7.28 \\
\hline & 3.0 & 11.76 & 10.89 & 107.25 & 4.24 & 297.67 & 8.13 \\
\hline SPD & 3.5 & 10.42 & 21.05 & 106.93 & 4.53 & 296.66 & 8.44 \\
\hline & 4.0 & 9.40 & 28.75 & 106.59 & 4.83 & 296.42 & 8.51 \\
\hline & 4.5 & 9.08 & 31.22 & 111.33 & 0.60 & 295.90 & 8.67 \\
\hline & 5.0 & 8.79 & 33.36 & 115.14 & 2.80 & 299.82 & 7.46 \\
\hline & 2.0 & 10.84 & 17.82 & 151.44 & 35.22 & 291.86 & 9.92 \\
\hline & 2.5 & 16.35 & 23.93 & 132.89 & 18.65 & 330.25 & 1.93 \\
\hline & 3.0 & 15.12 & 14.62 & 156.85 & 40.04 & 331.14 & 2.20 \\
\hline MPD & 3.5 & 10.46 & 20.72 & 131.80 & 17.68 & 289.52 & 10.64 \\
\hline & 4.0 & 13.80 & 4.56 & 201.07 & 79.53 & 298.53 & 7.86 \\
\hline & 4.5 & 13.08 & 0.85 & 127.64 & 13.97 & 297.01 & 8.33 \\
\hline & 5.0 & 9.59 & 27.32 & 108.80 & 2.86 & 293.27 & 9.49 \\
\hline & 2.0 & 14.03 & 6.32 & 115.32 & 2.96 & 298.37 & 7.91 \\
\hline & 2.5 & 12.78 & 3.16 & 106.29 & 5.10 & 299.12 & 7.68 \\
\hline & 3.0 & 12.04 & 8.78 & 107.24 & 4.25 & 296.71 & 8.42 \\
\hline RD & 3.5 & 10.76 & 18.44 & 106.04 & 5.32 & 292.33 & 9.77 \\
\hline & 4.0 & 9.73 & 26.24 & 106.41 & 4.99 & 294.11 & 9.23 \\
\hline & 4.5 & 9.16 & 30.58 & 111.06 & 0.84 & 291.08 & 10.16 \\
\hline & 5.0 & 8.84 & 33.03 & 116.92 & 4.39 & 295.16 & 8.90 \\
\hline
\end{tabular}

The damping ratio and the damping type were changed for the calibration of the model. Several values between $2 \%$ and $5 \%$ damping ratios were considered for three damping types. Numerical results show that the difference was $0.05 \%$ at $2.49 \%$ damping ratio for the type of SPD. This numerical result was converged until $5.73 \mathrm{sec}$. A difference of $0.03 \%$ was calculated for the type of MPD at $4.52 \%$ damping ratio (Fig. 9).

In the calculation of RD coefficients, combinations of $2.49 \%$ and $4.52 \%$ damping ratios, and natural frequencies of modes 1 and 3 were considered. Mode 3 for the first natural frequency at $2.49 \%$ damping ratio, mode 1 for the second natural frequency at $4.52 \%$ damping ratio were used in the first combination. Difference between numerical and experimental analysis results was observed as $2.11 \%$ for this combination. In the second combination, mode 3 for the first natural frequency at $4.52 \%$ damping ratio, mode 1 for the second natural frequency at $2.49 \%$ damping ratio were used. Difference between numerical and experimental results was calculated as $30.99 \%$ for the second combination. Numerical solutions for the first and the second combinations 
converged until 4.81 and 4.52 sec., respectively (Fig. 10). The first approximation has given better results than the second.

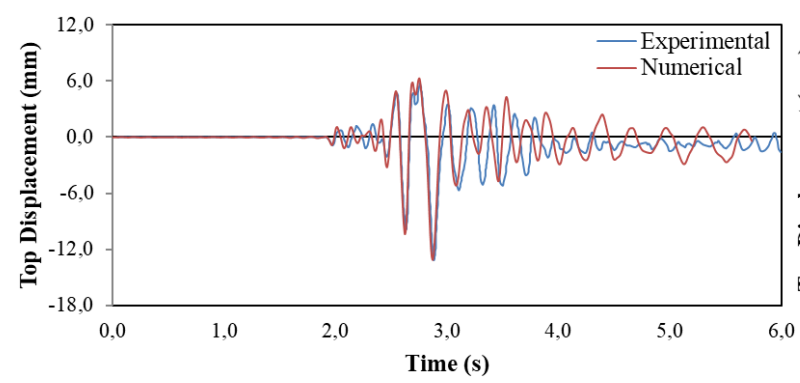

a) SPD at $2.49 \%$ damping ratio

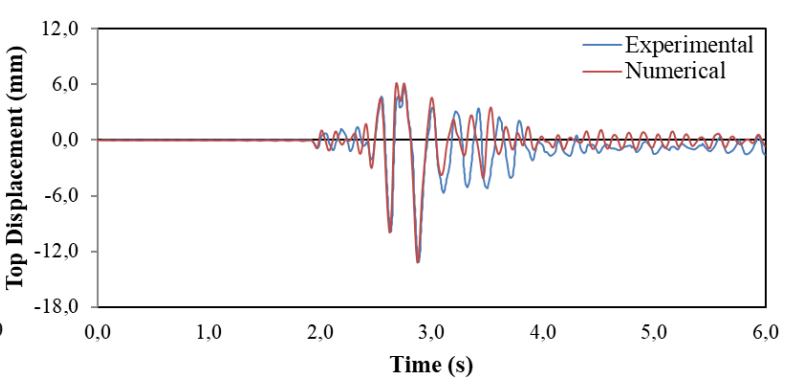

b) MPD at $4.52 \%$ damping ratio

Fig. 9 Top displacement responses of the CAMUS I for SPD and MPD types at the optimum damping ratios

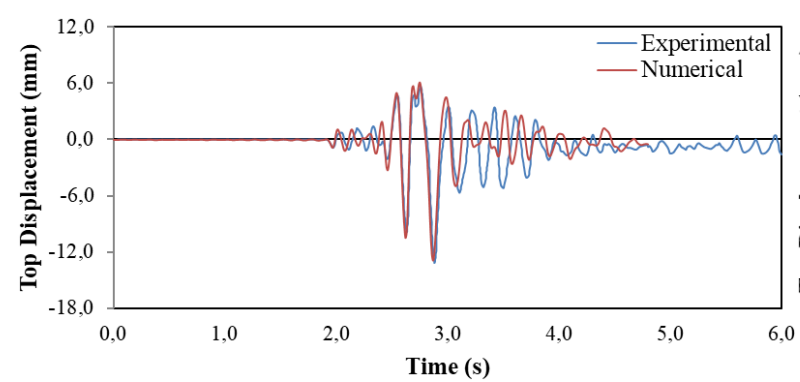

a) $2.49-4.52 \%$ damping ratios

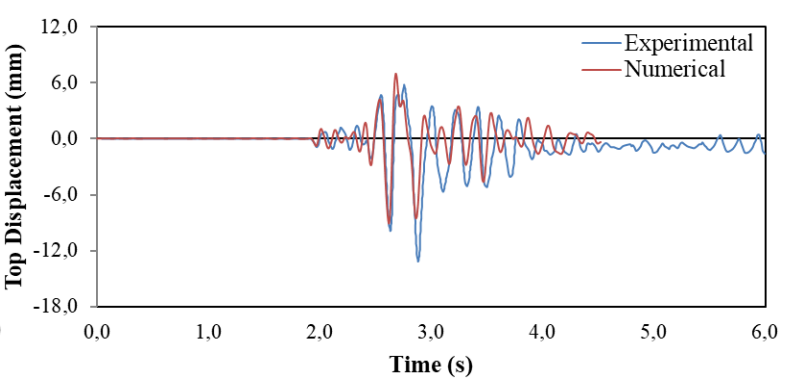

b) $4.52-2.49 \%$ damping ratios

Fig. 10 Top displacement responses of the CAMUS I for RD at the optimum damping ratios of the first two effective modes

Comparisons between damping types were implemented with respect to differences between numerical and experimental results regarding base shear force, absolute maximum roof displacement and overturning moment. For the roof displacement, provided that the damping ratio is between $2.5 \%$ and $3 \%$, the differences are less than $10.9 \%$ (except for MPD). The differences are less than 5.1\% (except for MPD) for the base shear forces and less than $8.5 \%$ for the overturning moments (Fig.11).

Nonlinear seismic analysis results exhibited good fit with the experimental results between 2.5 and 3.1 seconds. Amplitude and frequency divergences were seen after 3.1 seconds. Therefore, the time interval of 2.5 and 3.1 seconds was considered for the comparison of the top displacement time history graphs. Differences of roof displacement between numerical and experimental analysis are determined less than $3 \%$ at $2.49 \%, 4.52 \%$ and 2.49-4.52\% damping ratios for SPD, MPD and RD types, respectively. These three cases, which exhibit the best approximation within all analysis, were used during the investigation of the optimum $l_{f} / L_{w}$ ratio (optimum fiber element number). Fiber element number was modified to 100, 500, 750 and 1000 instead of 250. Numerical results with respect to the $l_{f} / L_{w}$ ratios are given in Table 3 .

The optimum ratios of $l_{f} / L_{w}$ were determined as $2.78 \%$ (250 fiber elements) for SPD and MPD types, as $11.20 \%$ (100 fiber elements) for RD type. Minimum differences between the absolute maximum roof displacement values of the CAMUS I structure obtained from the numerical and experimental analysis for SPD, MPD and RD solutions were computed as $0.05 \%$ at $2.49 \%$ damping ratio, $0.03 \%$ at $4.52 \%$ damping ratio and $0.41 \%$ at $2.49-4.52 \%$ damping ratios, respectively. On the other hand, when the $l_{f} / L_{w}$ ratio is selected less than $2.78 \%$ for the CAMUS I shear wall, differences of the roof displacement are less than $1 \%$ for SPD type in the FBFE method. 


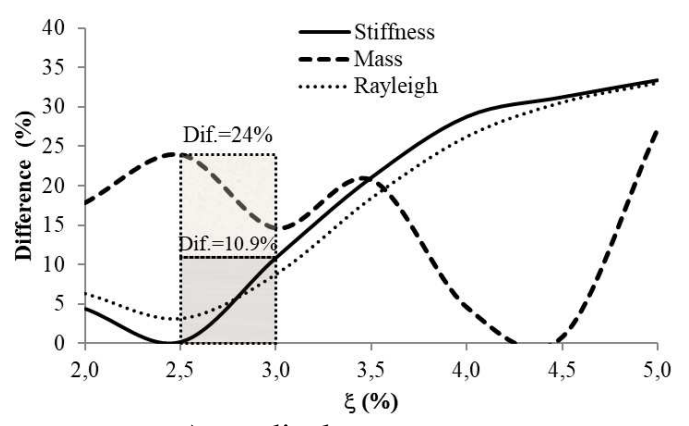

a) top displacement

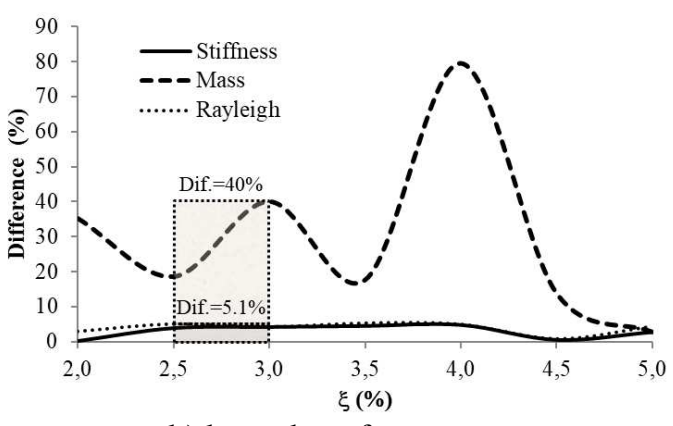

b) base shear force

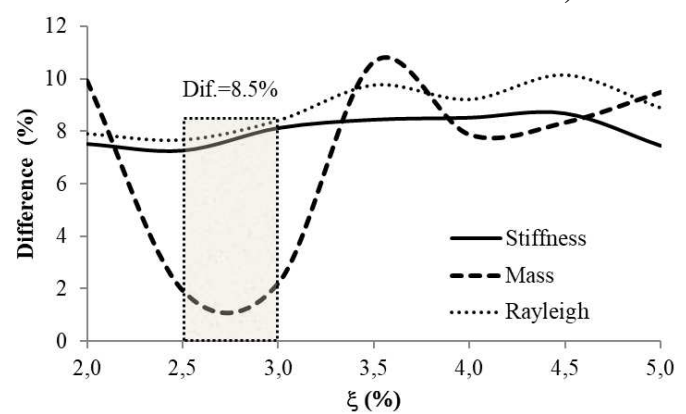

c) overturning moment

Fig. 11 Comparisons of absolute maximum values obtained by numerical analysis with experimental results of the CAMUS I structure for various damping types

Table 3 Comparison of absolute maximum top displacement values of CAMUS I structure for various number of fiber elements

\begin{tabular}{|c|c|c|c|c|c|c|c|}
\hline \multirow[b]{2}{*}{$\begin{array}{c}\text { Fiber } \\
\text { Element } \\
\text { Number }\end{array}$} & \multirow[b]{2}{*}{$\begin{array}{c}l_{f} / L_{w} \\
\text { Ratio } \\
(\%)\end{array}$} & \multicolumn{3}{|c|}{$\begin{array}{l}\text { Absolute Maximum } \\
\text { Top Displacement } \\
\text { (mm) }\end{array}$} & \multicolumn{3}{|c|}{$\begin{array}{c}\text { Difference between Numerical } \\
\text { Analysis and Experimental Results } \\
(\%)\end{array}$} \\
\hline & & $\begin{array}{c}\text { SPD } \\
2.49 \%\end{array}$ & $\begin{array}{l}\text { MPD } \\
4.52 \%\end{array}$ & $\begin{array}{c}\mathrm{RD} \\
2.49-4.52 \%\end{array}$ & $\begin{array}{c}\text { SPD } \\
2.49 \%\end{array}$ & $\begin{array}{l}\text { MPD } \\
4.52 \%\end{array}$ & $\begin{array}{c}\text { RD } \\
2.49-4.52 \%\end{array}$ \\
\hline 100 & 11.20 & 12.83 & 13.51 & 13.25 & 2.785 & 2.350 & 0.405 \\
\hline 250 & 2.78 & 13.19 & 13.20 & 12.92 & 0.053 & $\mathbf{0 . 0 3 0}$ & 2.114 \\
\hline 500 & 1.14 & 13.17 & 12.56 & 12.87 & 0.154 & 4.792 & 2.465 \\
\hline 750 & 0.76 & 13.10 & 13.09 & 12.87 & 0.683 & 0.774 & 2.460 \\
\hline 1000 & 0.62 & 13.12 & 12.99 & 12.87 & 0.601 & 1.560 & 2.483 \\
\hline
\end{tabular}

\subsection{Numerical Analysis of the NEES-UCSD Shear Wall}

A reinforced concrete shear wall structure constructed as seven-story by NEES (Network for Earthquake Engineering Simulation). It was seismically loaded on a shaking table at University of California at San Diego (UCSD) (Martinelli, 2007). This structure is composed of two types of shear walls located on the central axis and pier columns located on the corners of the structure. One of the shear walls is called as the web wall, while the other one is called as the flange wall. The walls were built as perpendicular to each other. The slab is connected to the flange wall and two shear walls are joined by slotted connections. The heights of basement and each floor are $0.76 \mathrm{~m}$ and $2.74 \mathrm{~m}$, respectively. Total height of the structure is $19.96 \mathrm{~m}$. The structure is fastened to the ground and its mass is 226 tons. Cross-sections of the flange wall and the web wall are different from each other. The width of the flange wall is $4.88 \mathrm{~m}$ and the thicknesses of the flange wall are $203 \mathrm{~mm}$ and $152 \mathrm{~mm}$ for the last floor and other floors, respectively. The width of the web wall is $3.65 \mathrm{~m}$ and the thickness of the web 
wall is $203 \mathrm{~mm}$ for the first and the last floor, while thickness of the web wall is $152 \mathrm{~mm}$ for other floors. The columns and shear walls supported $3.65 \times 8.13 \mathrm{~m}$ slabs at each floor. Post tensioned precast piers were joined to web wall and slabs via bracing. Details of the full-scale RC shear wall structure are shown in Fig. 12.
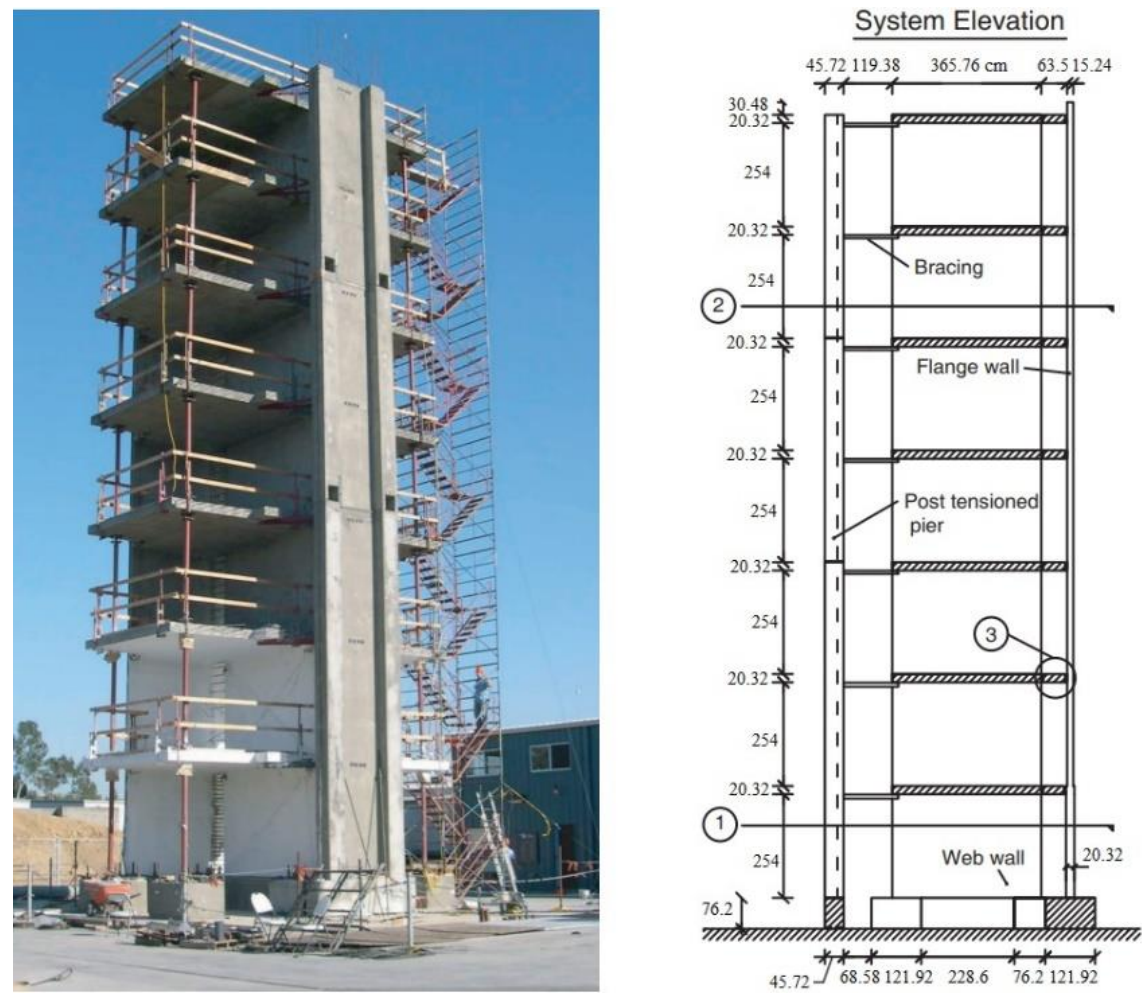

Fig. 12 NEES-UCSD structure (Martinelli, 2007)

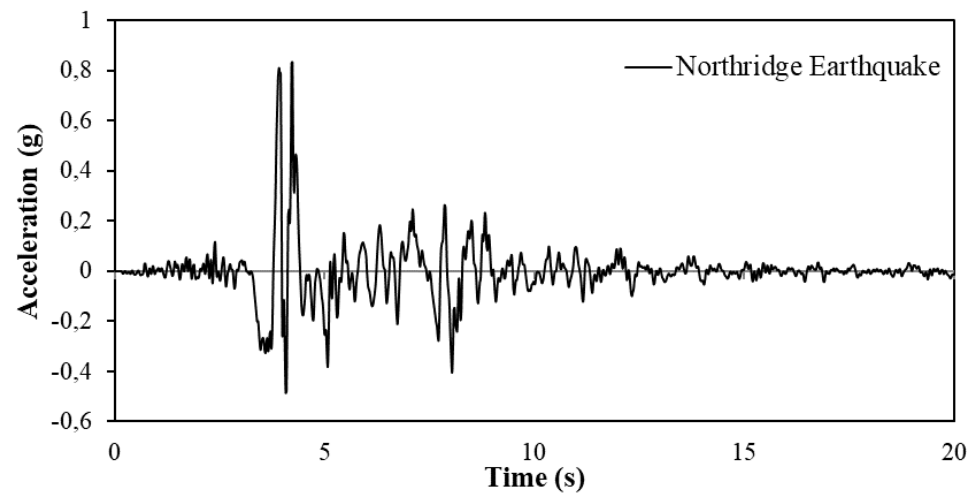

Fig. 13 The acceleration record of the 1994 Northridge earthquake (Seismosoft, 2016)

12.7 and $15.9 \mathrm{~mm}$ diameter steel ribbed bars were utilized for the longitudinal reinforcement of the web wall; $12.7 \mathrm{~mm}$ diameter steel ribbed bars were used for the longitudinal reinforcement of the flange wall. Diameter and spacing at the ends of both the shear walls of stirrups were $9.5 \mathrm{~mm} 101.6 \mathrm{~mm}$, respectively. The yield strength of the steel ribbed bars was $458.63 \mathrm{MPa}$ calculated by the mean of 11 specimens. The elasticity modulus and compressive strength of the concrete were 29.24 GPa and, 41.39 MPa respectively (Martinelli, 2007). The tensile strength of the concrete was calculated as $3.580 \mathrm{MPa}$ using Eq. (15). The 1994 Northridge earthquake acceleration record, which was obtained from the Sylmar Olive View Medical Centre, was used as the seismic input. The acceleration record of the earthquake is shown in Fig. 13. Magnitude of the earthquake 
was 6.7 according to the measured energy release. It can be observed from Fig. 13 that high acceleration values located on limited time intervals of the earthquake and its PGA value is 0.83g (Martinelli, 2007). According to experimental study, absolute maximum values of overturning moment and the shear force were determined at the base level as $11839.4 \mathrm{kN} \cdot \mathrm{m}$ and $1184.7 \mathrm{kN}$, respectively. The absolute maximum values of displacement were measured as $395 \mathrm{~mm}$ at the top of the structure.

In the seismic analysis of the NEES-UCSD structure using the FBFE method, 14 elements and 56 nodes were used for the model. The finite element model of the structure is illustrated in Fig. 14. Each element had four integration points. The maximum iteration numbers for the element solution and the global solution were 300 and 50, respectively.

Experimental results were compared with the numerical analysis results regarding the absolute maximum base overturning moment, base shear force, and roof displacement values, and time-history graphs of roof displacement of the structure. 250 fiber element numbers were chosen in the first solution stage. Thereafter, the number of fiber elements was modified in order to determine the ratio of optimum fiber element length.

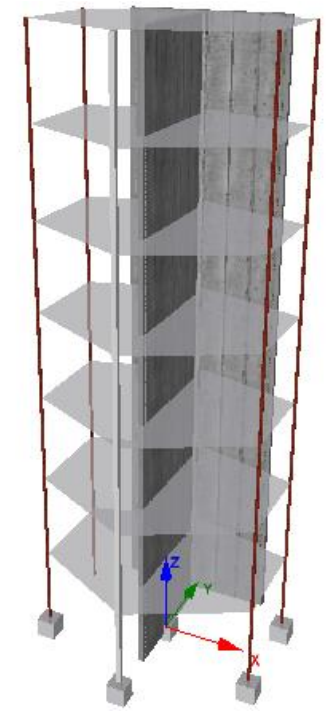

Fig. 14 3D view of the NEES-UCSD structure model

The natural frequencies for the structure were calculated according to percentages of effective modal mass and modal analysis results are shown in Table 4. As seen the table, the mass participation ratio of mode 3 was calculated as the highest value within all modes. Therefore, mode 3 was taken into consideration in the SPD and MPD calculations. In the RD computation, the natural frequencies of mode 3 and 4 were considered, since mass participation ratio of mode 4 has the second highest value within other modes.

Tangent stiffness matrix of the structure was used in order to calculate its damping matrix. Comparisons of numerical analysis and experimental results were conducted in terms of top displacement time-history graphs. The graphs were given in Figs. 15-17 for three damping ratios with SPD, MPD and RD types. The numerical convergence is observed for all steps of the nonlinear time-history analyses of the NEES-UCSD shear wall structure. 
Table 4 Eigenvalue analysis results of the NEES-UCSD

\begin{tabular}{cccccccc}
\hline Mode & Period & $\mathbf{U}_{\mathbf{x}}(\boldsymbol{\%})$ & $\mathbf{U}_{\mathbf{y}}(\boldsymbol{\%})$ & $\mathbf{U}_{\mathbf{z}}(\boldsymbol{\%})$ & $\mathbf{R}_{\mathbf{x}}(\boldsymbol{\%})$ & $\mathbf{R}_{\mathbf{y}}(\boldsymbol{\%})$ & $\mathbf{R}_{\mathbf{z}}(\boldsymbol{\%})$ \\
\hline $\mathbf{1}$ & 1.005847 & 0.00 & 0.01 & 0.06 & 0.13 & 0.00 & 0.06 \\
$\mathbf{2}$ & 0.514932 & 23.68 & 0.00 & 0.00 & 0.00 & 9.85 & 42.09 \\
$\mathbf{3}$ & $\mathbf{0 . 4 7 3 0 3 3}$ & 0.00 & $\mathbf{6 4 . 3 7}$ & 0.00 & 30.76 & 0.00 & 0.00 \\
$\mathbf{4}$ & $\mathbf{0 . 2 4 8 1 3 5}$ & $\mathbf{4 1 . 2 4}$ & 0.00 & 0.00 & 0.00 & 18.14 & 23.11 \\
$\mathbf{5}$ & 0.237939 & 0.00 & 0.14 & 0.01 & 0.24 & 0.04 & 0.68 \\
$\mathbf{6}$ & 0.085337 & 6.96 & 0.00 & 0.00 & 0.00 & 8.55 & 13.18 \\
$\mathbf{7}$ & 0.084365 & 0.00 & 0.00 & 48.48 & 0.01 & 0.00 & 0.00 \\
$\mathbf{8}$ & 0.077571 & 0.00 & 20.62 & 0.00 & 24.22 & 0.00 & 0.00 \\
$\mathbf{9}$ & 0.040835 & 13.60 & 0.00 & 0.00 & 0.00 & 14.75 & 6.96 \\
$\mathbf{1 0}$ & 0.030640 & 2.22 & 0.00 & 0.00 & 0.00 & 4.23 & 4.74 \\
$\mathbf{1 1}$ & 0.028455 & 0.00 & 0.00 & 5.08 & 0.00 & 0.00 & 0.00 \\
$\mathbf{1 2}$ & 0.028036 & 0.00 & 7.24 & 0.00 & 13.77 & 0.00 & 0.00 \\
$\mathbf{1 3}$ & 0.023701 & 0.00 & 0.87 & 0.02 & 6.07 & 0.00 & 0.00 \\
$\mathbf{1 4}$ & 0.022999 & 0.00 & 0.94 & 6.21 & 0.30 & 0.00 & 0.00 \\
$\mathbf{1 5}$ & 0.022942 & 0.00 & 0.37 & 10.29 & 5.10 & 0.00 & 0.00 \\
$\mathbf{1 6}$ & 0.020645 & 0.00 & 0.00 & 24.26 & 1.83 & 0.00 & 0.00 \\
$\mathbf{1 7}$ & 0.017759 & 0.00 & 0.01 & 1.64 & 0.12 & 0.00 & 0.00 \\
$\mathbf{1 8}$ & 0.015711 & 1.72 & 0.00 & 0.00 & 0.00 & 3.65 & 1.84 \\
$\mathbf{1 9}$ & 0.014860 & 0.00 & 0.09 & 0.62 & 0.85 & 0.00 & 0.00 \\
$\mathbf{2 0}$ & 0.014813 & 4.27 & 0.00 & 0.00 & 0.00 & 7.39 & 2.99 \\
$\mathbf{2 1}$ & 0.011901 & 0.00 & 0.04 & 0.72 & 0.23 & 0.00 & 0.00 \\
$\mathbf{2 2}$ & 0.009637 & 0.78 & 0.00 & 0.00 & 0.01 & 1.84 & 1.22 \\
$\mathbf{2 3}$ & 0.007607 & 2.54 & 0.03 & 0.01 & 0.05 & 5.43 & 0.93 \\
$\mathbf{2 4}$ & 0.007199 & 0.01 & 0.01 & 5.17 & 0.01 & 0.03 & 0.00 \\
$\mathbf{2 5}$ & 0.005184 & 1.40 & 0.30 & 0.01 & 0.64 & 3.40 & 0.06 \\
$\mathbf{2 6}$ & 0.001695 & 0.46 & 0.83 & 0.01 & 1.77 & 1.04 & 2.34 \\
\hline The bold values show the maximum mass participation ratio and the related periods. & & & & \\
\end{tabular}

The differences between numerical analysis obtained for the SPD, MPD, and RD types and experimental results are given in Table 5 for the damping ratios that vary between $2 \%$ and $5 \%$. The least differences of the absolute maximum roof displacement values between numerical and experimental results for SPD, MPD, and RD types were obtained as $1.56 \%$ at $3.5 \%$ damping ratio, $0.58 \%$ at $3.0 \%$ damping ratio and $0.25 \%$ at $3.0 \%$ damping ratio, respectively. The minimum differences of the absolute maximum base shear force values between numerical and experimental results for SPD, MPD, and RD types were obtained as $13.46 \%$ at $5.0 \%$ damping ratio, $23.08 \%$ at $5.0 \%$ damping ratio and $21.33 \%$ at $4.5 \%$ damping ratio, respectively. Additionally, the minimum differences of the absolute maximum base overturning moment values between numerical and experimental results for SPD, MPD, and RD types were obtained as $26.92 \%$ at $5.0 \%$ damping ratio, $34.84 \%$ at $2.0 \%$ damping ratio and $34.58 \%$ at $2.0 \%$ damping ratio, respectively.

The damping ratio and the damping type were changed to obtain the best approximation to experimental results. The differences were $0.29 \%$ and $0.58 \%$ between numerical and experimental results for SPD with damping ratio of $3.25 \%$ and for MPD with damping ratio of $3 \%$, respectively (Fig. 18). The RD coefficients were calculated by combinations of $3.25 \%$ and $3.00 \%$ damping ratios for natural frequencies of modes 3 and 4 . Solutions were obtained for $3.25 \%$ and $3.00 \%$ damping ratios with the natural frequencies of modes 3 and 4 , in the first combination, respectively. In the second combination, damping ratios of $3 \%$ and $3.25 \%$ were used for the natural frequencies of modes 3 and 4, respectively. Time-history graphs for the first and the second combinations are shown in Fig. 19. Differences of $2.48 \%$ and $0.08 \%$ were observed between numerical analysis and experimental results in the first and the second combinations, respectively. 
Table 5 The absolute maximum values obtained by numerical analyses and the comparison with experimental results of the CAMUS I structure for the damping ratios that vary between $2 \%$ and $5 \%$

\begin{tabular}{|c|c|c|c|c|c|c|c|}
\hline \multicolumn{2}{|c|}{ Damping } & \multicolumn{2}{|c|}{ Top Displacement } & \multicolumn{2}{|c|}{ Base Shear Force } & \multicolumn{2}{|c|}{ Overturning Moment } \\
\hline $\begin{array}{l}\text { Damping } \\
\text { Type }\end{array}$ & $\begin{array}{c}\text { Damping } \\
\text { Ratio } \\
(\%)\end{array}$ & $\begin{array}{c}\text { Absolute } \\
\text { maximum } \\
(\mathbf{m m})\end{array}$ & $\begin{array}{c}\text { Difference } \\
\text { between } \\
\text { Exp. and } \\
\text { Num. } \\
\text { Analysis } \\
(\%)\end{array}$ & $\begin{array}{c}\text { Absolute } \\
\text { maximum } \\
(k N)\end{array}$ & $\begin{array}{c}\text { Difference } \\
\text { between } \\
\text { Exp. and } \\
\text { Num. } \\
\text { Analysis } \\
(\%)\end{array}$ & $\begin{array}{c}\text { Absolute } \\
\text { maximum } \\
(\text { kN.m) }\end{array}$ & $\begin{array}{c}\text { Difference } \\
\text { between } \\
\text { Exp. and } \\
\text { Num. } \\
\text { Analysis } \\
(\%)\end{array}$ \\
\hline \multirow{7}{*}{ SPD } & 2.0 & 434.85 & 10.09 & 942.75 & 20.42 & 8171.53 & 30.98 \\
\hline & 2.5 & 418.04 & 5.83 & 979.25 & 17.34 & 8205.66 & 30.69 \\
\hline & 3.0 & 401.69 & 1.69 & 999.35 & 15.65 & 8310.17 & 29.81 \\
\hline & 3.5 & 388.83 & 1.56 & 980.59 & 17.23 & 8474.23 & 28.42 \\
\hline & 4.0 & 374.83 & 5.11 & 992.87 & 16.19 & 8389.46 & 29.14 \\
\hline & 4.5 & 359.01 & 9.11 & 979.15 & 17.35 & 8401.22 & 29.04 \\
\hline & 5.0 & 345.90 & 12.43 & 1025.18 & 13.46 & 8652.01 & 26.92 \\
\hline \multirow{7}{*}{ MPD } & 2.0 & 427.26 & 8.17 & 751.57 & 36.56 & 7714.63 & 34.84 \\
\hline & 2.5 & 408.92 & 3.52 & 768.55 & 35.13 & 7617.18 & 35.66 \\
\hline & 3.0 & 392.71 & 0.58 & 777.33 & 34.39 & 7513.34 & 36.54 \\
\hline & 3.5 & 375.82 & 4.86 & 789.08 & 33.39 & 7420.86 & 37.32 \\
\hline & 4.0 & 355.81 & 9.92 & 887.28 & 25.11 & 7372.18 & 37.73 \\
\hline & 4.5 & 344.82 & 12.70 & 871.59 & 26.43 & 7391.74 & 37.57 \\
\hline & 5.0 & 331.37 & 16.11 & 911.29 & 23.08 & 7356.02 & 37.87 \\
\hline \multirow{7}{*}{ RD } & 2.0 & 428.05 & 8.37 & 817.91 & 30.96 & 7745.92 & 34.58 \\
\hline & 2.5 & 410.01 & 3.80 & 854.18 & 27.90 & 7678.84 & 35.14 \\
\hline & 3.0 & 394.00 & 0.25 & 862.50 & 27.20 & 7629.64 & 35.56 \\
\hline & 3.5 & 378.89 & 4.08 & 901.33 & 23.92 & 7591.59 & 35.88 \\
\hline & 4.0 & 363.86 & 7.88 & 924.58 & 21.96 & 7505.11 & 36.61 \\
\hline & 4.5 & 351.16 & 11.10 & 931.99 & 21.33 & 7460.55 & 36.99 \\
\hline & 5.0 & 338.93 & 14.19 & 930.80 & 21.43 & 7445.20 & 37.12 \\
\hline
\end{tabular}

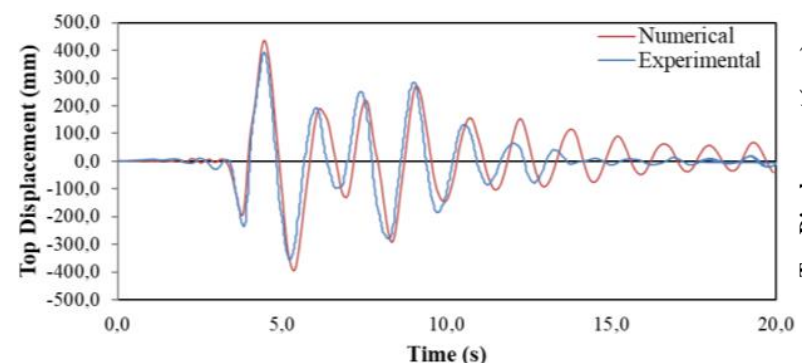

a) SPD

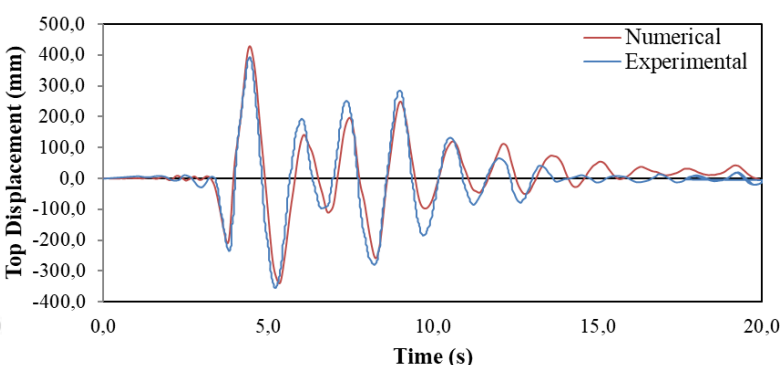

b) MPD

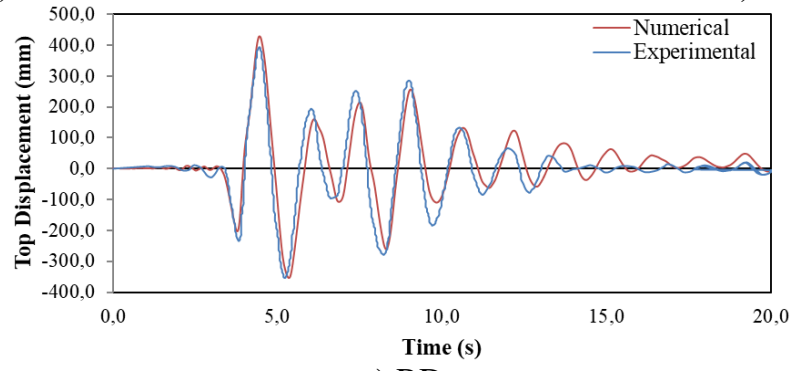

c) RD

Fig. 15 Top displacement responses of the CAMUS I for the damping ratio of $2 \%$ 


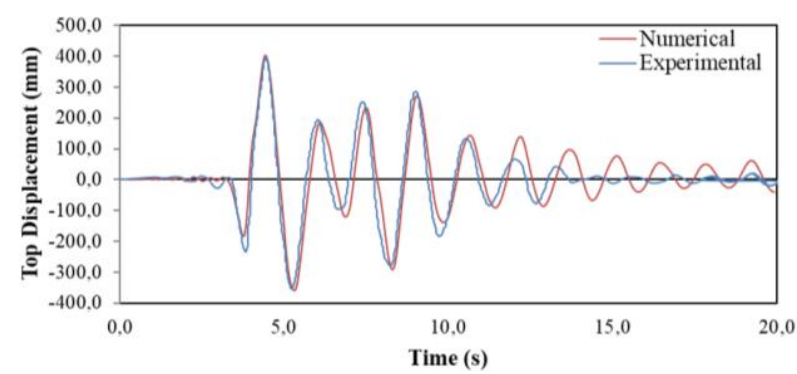

a) SPD

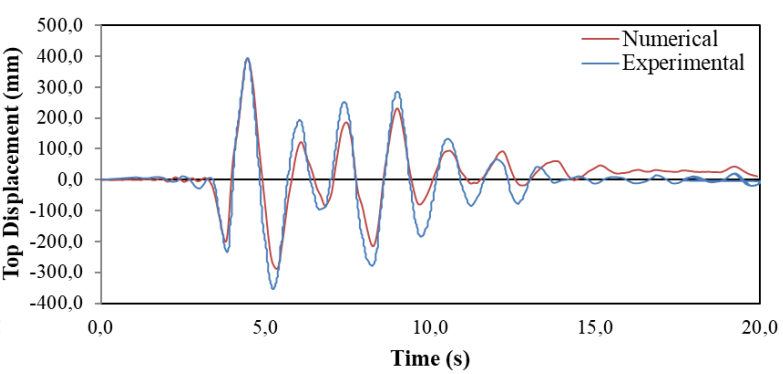

b) MPD

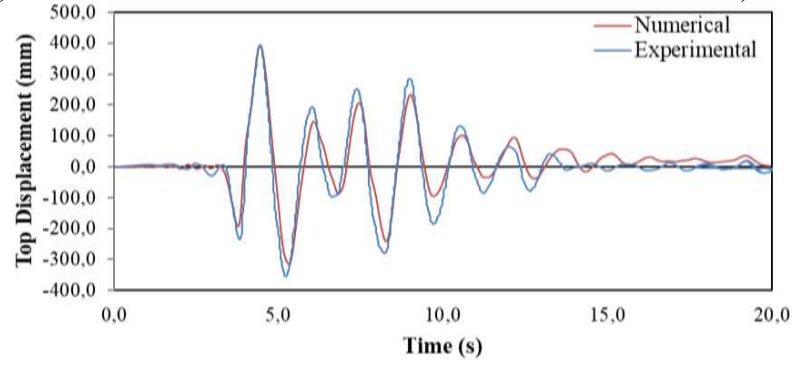

c) $\mathrm{RD}$

Fig. 16 Top displacement responses of the CAMUS I for the damping ratio of $3 \%$

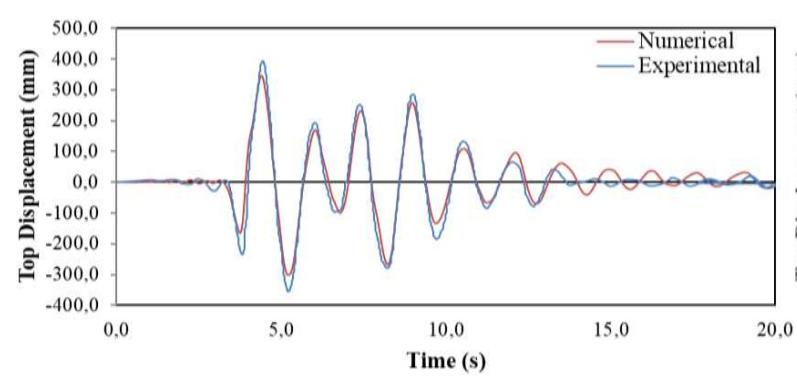

a) SPD

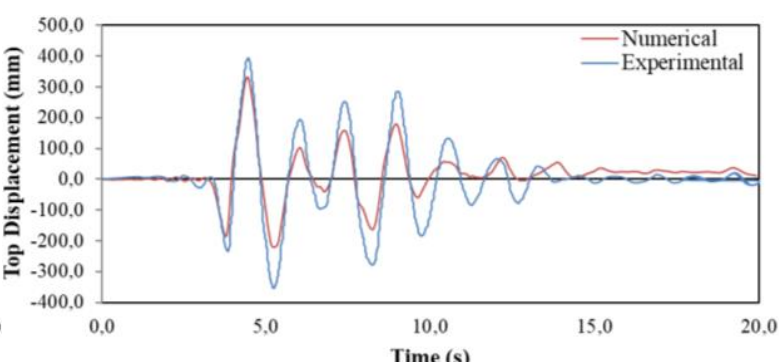

b) MPD

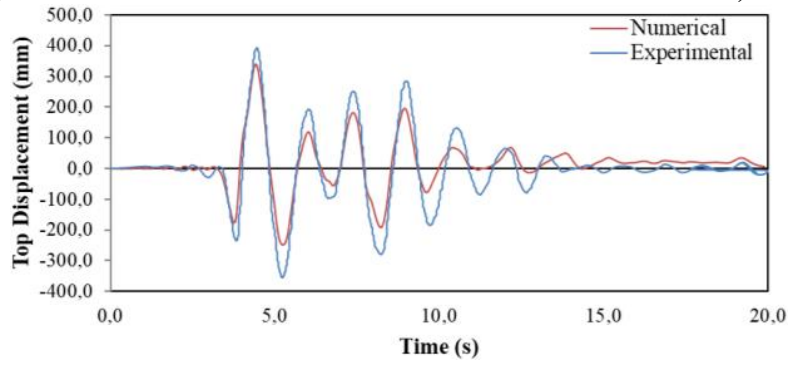

c) $\mathrm{RD}$

Fig. 17 Top displacement responses of the CAMUS I for the damping ratio of 5\%

The damping types were compared with respect to differences between numerical and experimental results considering absolute maximum base overturning moment, base shear force, and roof displacement. For the roof displacements, provided that the damping ratio is between $2.5 \%$ and $3.5 \%$, the differences are defined less than $5.9 \%$. The differences for the base shear forces and the overturning moments were defined less than $35.2 \%$ and $37.4 \%$, respectively (Fig. 20).

Nonlinear seismic analysis results exhibited good fit with the experimental results between 4 and 10 seconds. Amplitude and frequency discrepancies were seen after 10 seconds. Therefore, the time interval of 4 and 10 seconds was considered for the comparison of the top displacement graph. Non-significance differences were observed between solutions for the last four conditions; SPD at 3.25\% damping ratio, MPD at 3.00\% damping ratio, $\mathrm{RD}$ at 3.00-3.25\% damping ratios and $\mathrm{RD}$ at 3.25-3.00\% damping ratios. Differences of top displacement values are less than $1 \%$ in first three conditions. Optimum fiber element number was specified by 
taking into account results of these three conditions. 70, 80, 90, 100, 250, 500, 750 and 1000 fiber elements were used and obtained numerical results were given with the $l_{f} / L_{w}$ ratio in Table 6 .

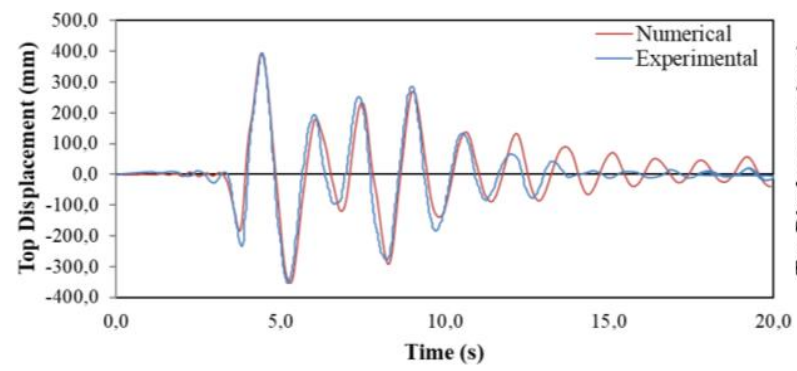

a) SPD at $3.25 \%$ damping ratio

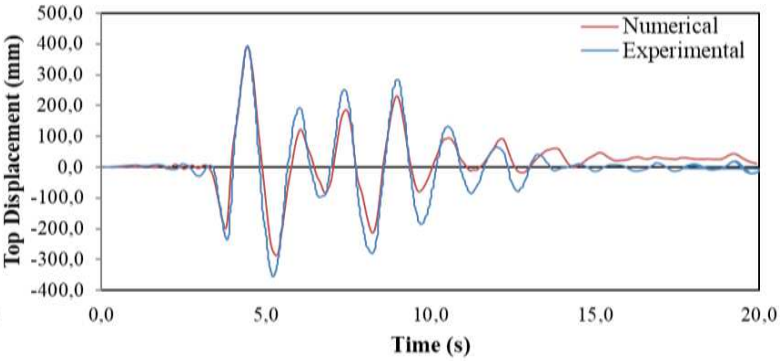

b) MPD at $3.00 \%$ damping ratio

Fig. 18 Top displacement responses of the NEES-UCSD for SPD and MPD types at optimum damping ratios

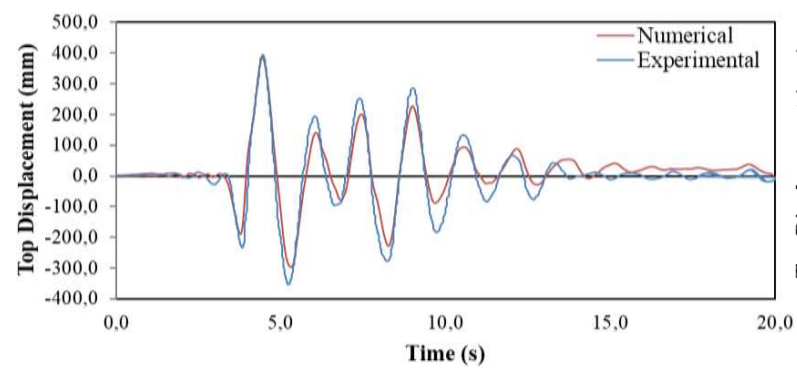

a) $3.25-3.00 \%$ damping ratios

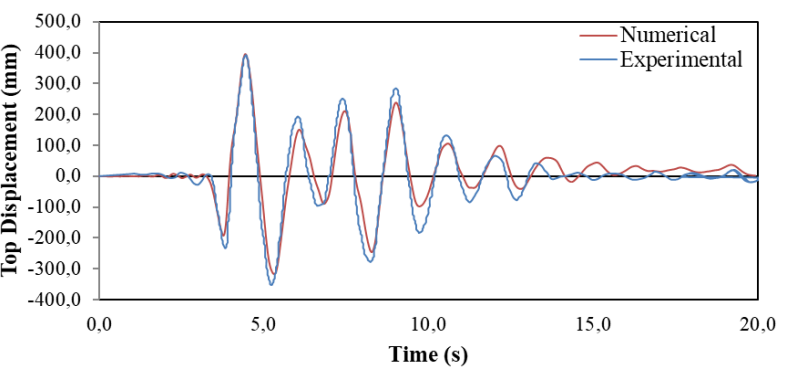

b) $3.00-3.25 \%$ damping ratios

Fig. 19 Top displacement responses of the NEES-UCSD for RD type at the optimum damping ratios of the first two effective modes

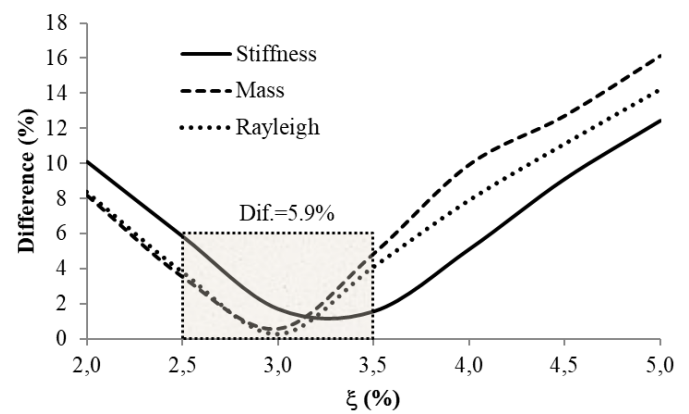

a) top displacement

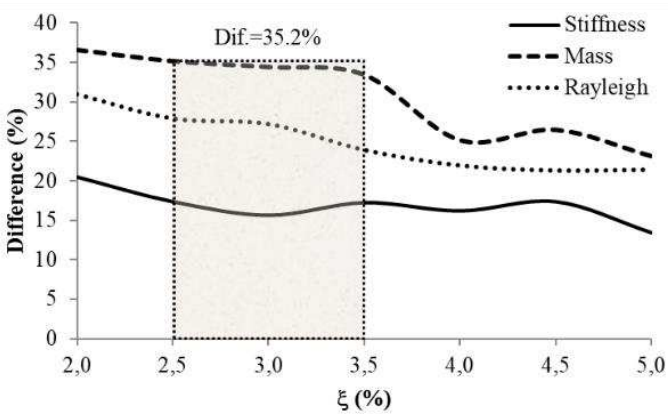

b) base shear force

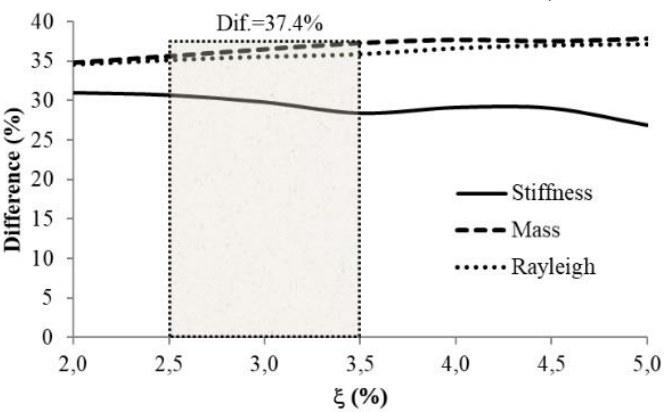

c) overturning moment

Fig. 20 Comparisons of absolute maximum values obtained by numerical analysis with experimental results of the NEES-UCSD structure for various damping types

The optimum ratios of $l_{f} / L_{w}$ for SPD, MPD, and RD types were determined as $15.20 \%$ (90 fiber elements), $10.87 \%$ (100 fiber elements), and 2.81\% (250 fiber elements), respectively. The least differences of the roof displacement values between numerical and experimental results by using these optimum $l_{f} / L_{w}$ ratios 
are calculated as $0.034 \%, 0.041 \%$, and $0.079 \%$ for SPD, MPD, and RD types, respectively. Differences regarding the roof displacement are less than $0.7 \%$ for all the damping types in the FBFE method, provided that fiber element length is selected less than $10.87 \%$ of longitudinal length of shear wall (100 or more number of fiber element).

Table 6 Comparison of absolute maximum top displacement values of NEES-UCSD structure for various number of fiber elements

\begin{tabular}{cccccccc}
\hline & & \multicolumn{3}{c}{$\begin{array}{c}\text { Absolute Maximum } \\
\text { Top Displacement } \\
(\mathbf{m m})\end{array}$} & \multicolumn{2}{c}{$\begin{array}{c}\text { Difference between Numerical } \\
\text { Analysis and Experimental Results } \\
\text { (\%) }\end{array}$} \\
\hline $\begin{array}{c}\text { Fiber } \\
\text { Element }\end{array}$ & $\begin{array}{c}\boldsymbol{l}_{\boldsymbol{f}} / \boldsymbol{L}_{\boldsymbol{w}} \\
\text { Ratio }\end{array}$ & $\mathrm{SPD}$ & $\mathrm{MPD}$ & $\mathrm{RD}$ & $\mathrm{SPD}$ & $\mathrm{MPD}$ & $\mathrm{RD}$ \\
Number & $\mathbf{( \% )}$ & $3.25 \%$ & $3.00 \%$ & $3.0-3.25 \%$ & $3.25 \%$ & $3.00 \%$ & $3.0-3.25 \%$ \\
\hline 70 & 43.50 & 400.85 & 391.18 & 401.28 & 1.481 & 0.968 & 1.591 \\
80 & 21.75 & 396.47 & 390.17 & 396.87 & 0.373 & 1.224 & 0.474 \\
90 & 15.20 & 395.13 & 390.36 & 397.63 & $\mathbf{0 . 0 3 4}$ & 1.175 & 0.666 \\
100 & 10.87 & 393.87 & 395.16 & 396.07 & 0.286 & $\mathbf{0 . 0 4 1}$ & 0.270 \\
250 & 2.81 & 393.87 & 392.71 & 394.69 & 0.286 & 0.581 & $\mathbf{0 . 0 7 9}$ \\
500 & 1.36 & 393.80 & 392.49 & 394.22 & 0.303 & 0.636 & 0.198 \\
750 & 0.98 & 396.10 & 392.41 & 394.05 & 0.280 & 0.656 & 0.241 \\
1000 & 0.71 & 395.82 & 392.78 & 394.13 & 0.209 & 0.563 & 0.221 \\
\hline The bold values show the minimum differences. & & & & & &
\end{tabular}

\subsection{Comparison of CAMUS I and NEES-UCSD shear wall structures}

Comparison of NEES-UCSD and CAMUS I shear wall structures were achieved to investigate the efficiency of FBFE method. In the comparisons, the absolute maximum values of the overturning moment, the base shear force and the roof displacement were used for all damping types and the damping ratios that selected between $2 \%$ and $5 \%$.

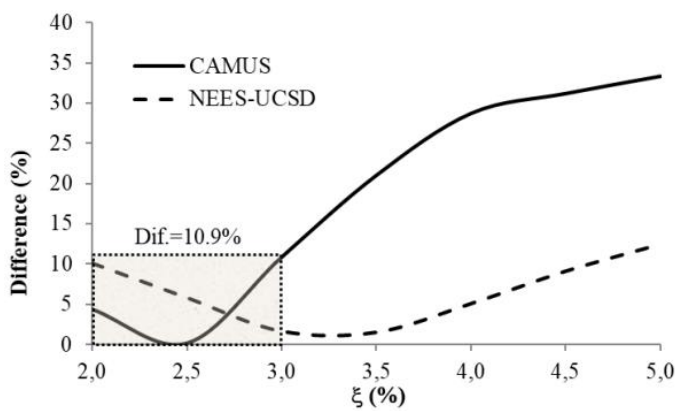

a) top displacement

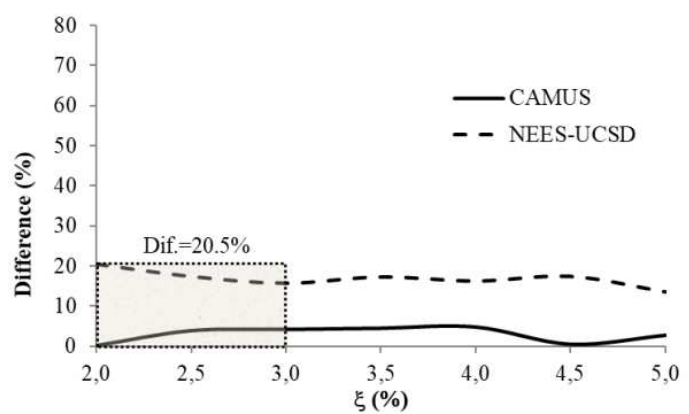

b) base shear force

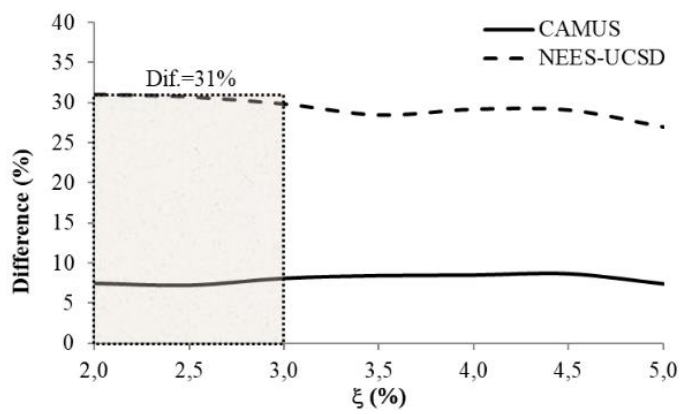

c) overturning moment

Fig. 21 Comparisons of absolute maximum values obtained by numerical analysis with experimental results of the both shear wall structures for SPD 


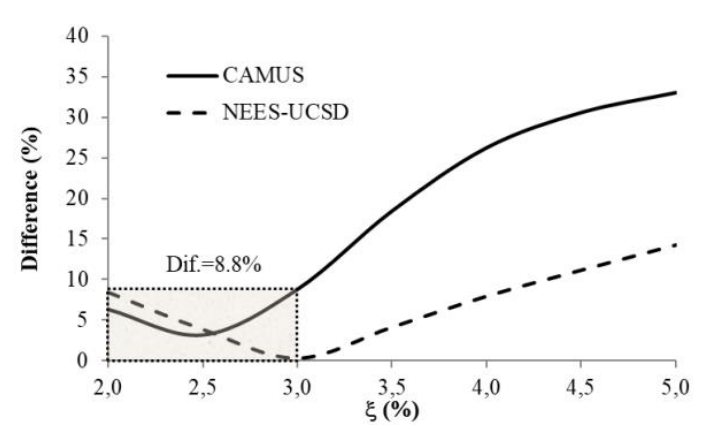

a) top displacement

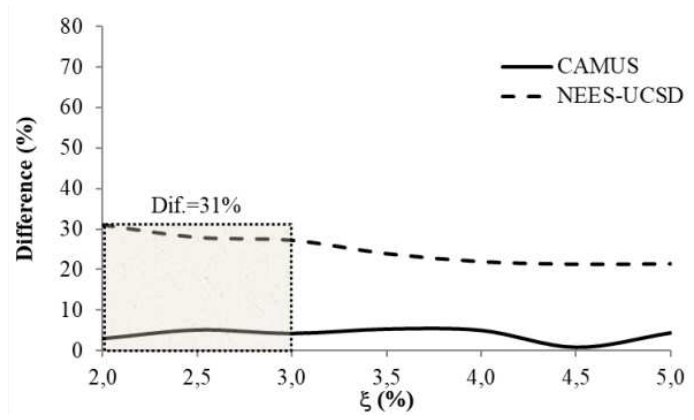

b) base shear force

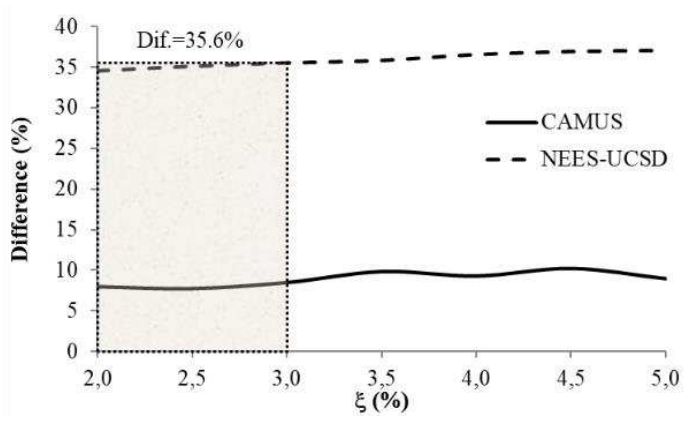

c) overturning moment

Fig. 22 Comparisons of absolute maximum values obtained by numerical analysis with experimental results of the both shear wall structures for RD

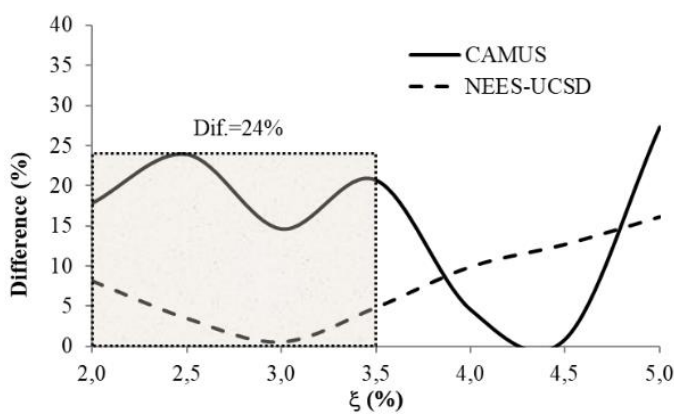

a) top displacement

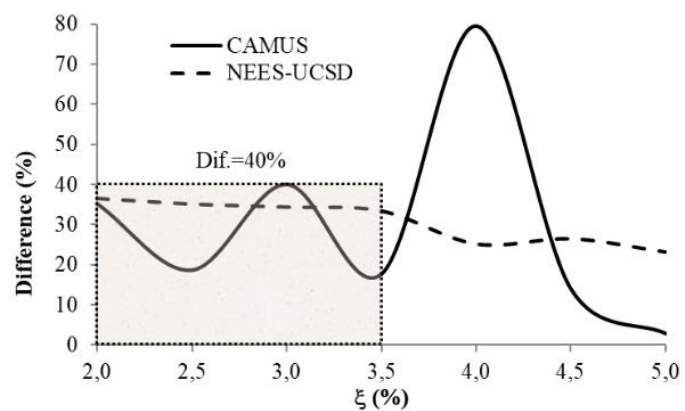

b) base shear force

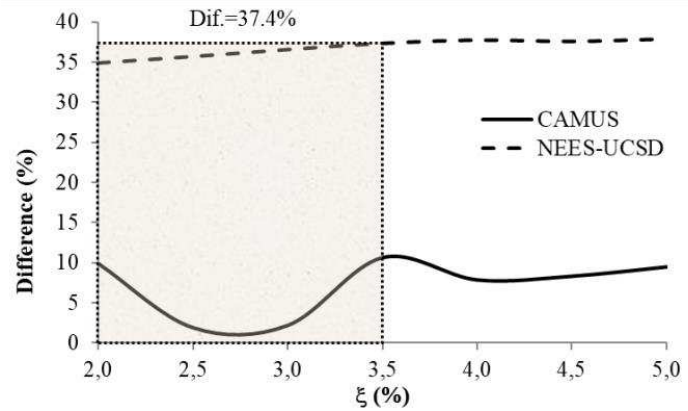

c) overturning moment

Fig. 23 Comparisons of absolute maximum values obtained by numerical analysis with experimental results of the both shear wall structures for MPD

The differences of the roof displacement, the base shear force and the overturning moment results for SPD with the damping ratios that vary between $2.0 \%$ and $3.0 \%$ are less than $10.9 \%, 20.4 \%$ and $31.0 \%$, respectively (Fig. 21). The differences of the roof displacement, the base shear force and the overturning moment results for RD with the damping ratios that vary between $2.0 \%$ and $3.0 \%$ are less than $8.8 \%, 31.0 \%$ and $35.6 \%$, respectively (Fig. 22). However, regarding MPD, the differences of the roof displacement, the base shear force 
and the overturning moment results for the damping ratios that vary between $2.0 \%$ and $3.5 \%$ are less than $24.0 \%$, $40.0 \%$ and $37.4 \%$, respectively (Fig.23).

\section{Conclusions}

In this research, numerical simulation of two RC shear wall structures are conducted to investigate the efficiency of the force-based Fiber Element Method on nonlinear seismic response of the walls. The numerical analysis results are compared with experimental shaking table test results of NEES-UCSD and CAMUS I shear wall structures. Comparisons are carried out regarding the absolute maximum values of the overturning moment, the base shear force, and the roof displacement, and time-history graphs of roof displacements. Dynamic properties of the structures are determined with eigenvalue analysis. Stiffness-proportional damping, mass-proportional damping, and Rayleigh damping types are used for the damping ratios that vary between $2 \%$ and $5 \%$ in the numerical analyses. Optimum damping ratios are specified for each damping type by using a constant fiber element number (250). To observe the effectiveness of fiber element number on the solutions, the different number of fiber element $(70,80,90,100,500,750$, and 1000) are selected in each cross-section of the structural element. The optimum number of fiber element is defined by considering the $\left(l_{f} / L_{w}\right)$ ratio. According to comparisons of experimental and numerical analysis results, the following outcomes for the FBFE method can be expressed as;

- Differences of the roof displacement, the base shear force, and the overturning moment results for stiffness-proportional damping at the damping ratios between $2.0 \%$ and $3.0 \%$ are less than $10.9 \%$, $20.5 \%$, and $31.0 \%$, respectively.

- In Rayleigh damping type, differences of the roof displacement, the base shear force, and the overturning moment results at the damping ratios between $2.0 \%$ and $3.0 \%$ are less than $8.8 \%, 31.0 \%$, and $35.6 \%$ respectively.

- Differences of the roof displacement, the base shear force, and the overturning moment results at the damping ratios between $2.0 \%$ and $3.5 \%$ are less than $24.0 \%, 40.0 \%$, and $37.4 \%$, respectively for massproportional damping.

- The minimum differences of the roof displacement values between numerical and experimental results for the NEES-UCSD and CAMUS I structures are calculated at $3.25 \%$ and at $2.49 \%$ damping ratios, respectively for the stiffness-proportional damping. For the mass-proportional damping, the least differences for the NEES-UCSD and CAMUS I structures are computed for $3.00 \%$ and for $4.52 \%$ damping ratios, respectively.

- Provided that the $l_{f} / L_{w}$ ratio is smaller than $3 \%$ at the optimum damping ratios, the differences between numerical and experimental results in both shear wall structures are computed less than $2.5 \%$ for stiffness-proportional and Rayleigh damping types. An inconsistent result is obtained for massproportional damping at the optimum damping ratio.

- Stiffness-proportional and Rayleigh damping types give better results than mass-proportional damping. Therefore, these two damping types for the damping ratios that vary between $2-3 \%$ are usable in nonlinear seismic analysis of RC shear wall structures with the force-based Fiber Element Method. 


\section{DECLARATIONS}

\section{Funding}

The authors did not receive any funding to conduct this study.

\section{Compliance with ethical standards}

\section{Conflicts of interest}

All authors have participated in (a) conception and design, or analysis and interpretation of the data; (b) drafting the article or revising it critically for important intellectual content; and (c) approval of the final version.

The authors declare that they have no conflicts of interest relevant to the content of this article.

\section{Availability of data and material}

Available upon request

\section{Acknowledgements}

This study has been prepared according to Ömer Faruk Osmanlı's M.Sc. thesis results and we would like to thank Mehmet Eren Gülşan and Muhammet Karaton, supervisors of this thesis.

\section{References}

ACI 318-02 (1999), Building code requirements for structural concrete and commentary. American Concrete Institute, Farmington Hills, MI, USA

Calayir Y, Karaton M (2005) A continuum damage concrete model for earthquake analysis of concrete gravity $\begin{array}{llllll}\text { dam-reservoir } & \text { systems. } & \text { Soil } & \text { Dyn.\&Earth } & \text { Eng } & \text { 25(11): }\end{array}$ https://doi.org/10.1016/j.soildyn.2005.05.003

Celep Z, Kumbasar N (2004) Deprem mühendisliğine giriş ve depreme dayanıklı yapı tasarımı. Beta Dagitim, Istanbul, Turkey

Correia AA, Virtuoso FBE (2006) Nonlinear Analysis of Space Frames. In: Proceedings of the Third European Conference on Computational Mechanics: Solids, Structures and Coupled Problems in Engineering, Springer, Dordrecht, Lisbon, Portugal, pp 107-107. https://doi.org/10.1007/1-4020-5370-3 107

Dashti F, Dhakal RP, Pampanin S (2017) Numerical modeling of rectangular reinforced concrete structural walls. J Struc Eng 143(6): 04017031. https://doi.org/10.1061/(ASCE)ST.1943-541X.0001729

Feng DC, Ren XD, Li J (2018) Cyclic behavior modeling of reinforced concrete shear walls based on softened damage-plasticity model. Eng Struc 166: 363-375. https://doi.org/10.1016/j.engstruct.2018.03.085

Feng DC, Xu J (2018) An efficient fiber beam-column element considering flexure-shear interaction and anchorage bond-slip effect for cyclic analysis of RC structures. Bull Earthq Eng 16(11): 5425-5452. https://doi.org/10.1007/s10518-018-0392-y

Fritz WP, Jones NP, Igusa T (2009) Predictive models for the median and variability of building period and damping. J Struc Eng 135(5): 576-586. https://doi.org/10.1061/(ASCE)0733-9445(2009)135:5(576)

Gilles D, McClure G (2012) In situ dynamic characteristics of reinforced concrete shear wall buildings. In: Structures Congress 2012, Chicago, Illinois, United States, pp. 2235-2245. https://doi.org/10.1061/9780784412367.196

Huang ST, Huang YS, He A, Tang XL, Chen QJ, Liu X, Cai J (2018) Experimental study on seismic behaviour of an innovative composite shear wall. Journal of Constructional Steel Research 148: 165-179. https://doi.org/10.1016/j.jcsr.2018.05.003

Karaton M (2014) Comparisons of elasto fiber and fiber bernoulli-euler reinforced concrete beam-column elements. Struc Eng\& Mech 51(1): 89-110. https://doi.org/10.12989/sem.2014.51.1.089

Kazaz I, Yakut A, Gülkan P (2006) Numerical simulation of dynamic shear wall tests: A benchmark study. Comp\&Struc 84(8-9): 549-562. https://doi.org/10.1016/j.compstruc.2005.11.002

Kolozvari K, Tran TA, Orakcal K, Wallace JW (2015) Modeling of cyclic shear-flexure interaction in reinforced 
concrete structural walls. II: Experimental validation. J Struc Eng 141(5): 04014136. https://doi.org/10.1061/(ASCE)ST.1943-541X.0001083

Li ZX, Gao Y, Zhao Q (2016) A 3D flexure-shear fiber element for modeling the seismic behavior of reinforced concrete columns. Eng Struc 117: 372-383. https://doi.org/10.1016/j.engstruct.2016.02.054

Li G, Yu DH, Li HN (2018) Seismic response analysis of reinforced concrete frames using inelasticity-separated fiber beam-column model. Earth Eng\&Struc Dyn, 47(5): 1291-1308. https://doi.org/10.1002/eqe.3018

Mander JB, Priestley MJ, Park R (1988) Theoretical stress-strain model for confined concrete. J Struc Eng 114(8): 1804-1826. https://doi.org/10.1061/(ASCE)0733-9445(1988)114:8(1804)

Martinelli L, Martinelli P, Mulas MG (2013) Performance of fiber beam-column elements in the seismic analysis of a lightly reinforced shear wall. Eng Struc 49: 345-359 http://dx.doi.org/10.1016/j.engstruct.2012.11.010

Martinelli P (2007) Shaking table tests on rc shear walls: significance of numerical modeling. Dissertation, Politecnico di Milano, Italy

Martinelli P, Filippou FC (2009) Simulation of the shaking table test of a seven-story shear wall building. Earth Eng\&Struc Dyn 38(5): 587-607. https://doi.org/10.1002/eqe.897

Menegotto M, Pinto PE (1973) Method of analysis for cyclically loaded RC plane frames including changes in geometry and non-elastic behaviour of elements under combined normal force and bending. In: Proceedings of IABSE symposium on resistance and ultimate deformability of structures acted on by well defined repeated loads, Lisbon, pp 15-22

Nikolić Ž, Živaljić N, Smoljanović H, Balić I (2017) Numerical modelling of reinforced-concrete structures under seismic loading based on the finite element method with discrete inter-element cracks. Earth Eng\&Struc Dyn, 46(1): 159-178. https://doi.org/10.1002/eqe.2780

Orakcal K, Wallace JW, Conte JP (2004) Flexural modeling of reinforced concrete walls-model attributes. Struc J, 101(5): 688-698. https://doi.org/10.14359/13391

Peterman KD, Stehman MJ, Madsen RL, Buonopane SG, Nakata N, Schafer BW (2016) Experimental seismic response of a full-scale cold-formed steel-framed building. II: Subsystem-level response. J Struc Eng, 142(12): 04016128. https://doi.org/10.1061/(ASCE)ST.1943-541X.0001578

Rong XL, Zheng SS, Zhang YX, Zhang XY, Dong LG (2020) Experimental study on the seismic behavior of RC shear walls after freeze-thaw damage. Eng Struc, 206: 110101. https://doi.org/10.1016/j.engstruct.2019.110101

Seismosoft (2016), SeismoStruct 2016 - A computer program for static and dynamic nonlinear analysis of framed structures. Available from http://www.seismosoft.com

Shen D, Yang Q, Jiao Y, Cui Z, Zhang J (2017) Experimental investigations on reinforced concrete shear walls strengthened with basalt fiber-reinforced polymers under cyclic load. Constr Build Mater, 136, 217-229. https://doi.org/10.1016/j.conbuildmat.2016.12.102

Taucer FF, Spacone E, Filippou FC (1991) A fiber beam-column element for seismic response analysis of reinforced concrete structures, Report No. UCB/EERC-91/17, Earthquake Engineering Research Center, College of Engineering, University of California, Berkeley

Vásquez JA, Juan C, de la L, Matías H (2016) A regularized fiber element model for reinforced concrete shear walls. Earth Eng\&Struc Dyn 45: 2063-2083. https://doi.org/10.1002/eqe.2731

Wang W, Wang Y, Lu Z (2018) Experimental study on seismic behavior of steel plate reinforced concrete composite shear wall. Eng Struc 160: 281-292. https://doi.org/10.1016/j.engstruct.2018.01.050

Zhang S, Cheng M, Wang J, Wu JY (2020) Modeling the hysteretic responses of RC shear walls under cyclic loading by an energy-based plastic-damage model for concrete. Int J Damage Mech 29(1): 184-200. https://doi.org/10.1177/1056789519889103 
Figures

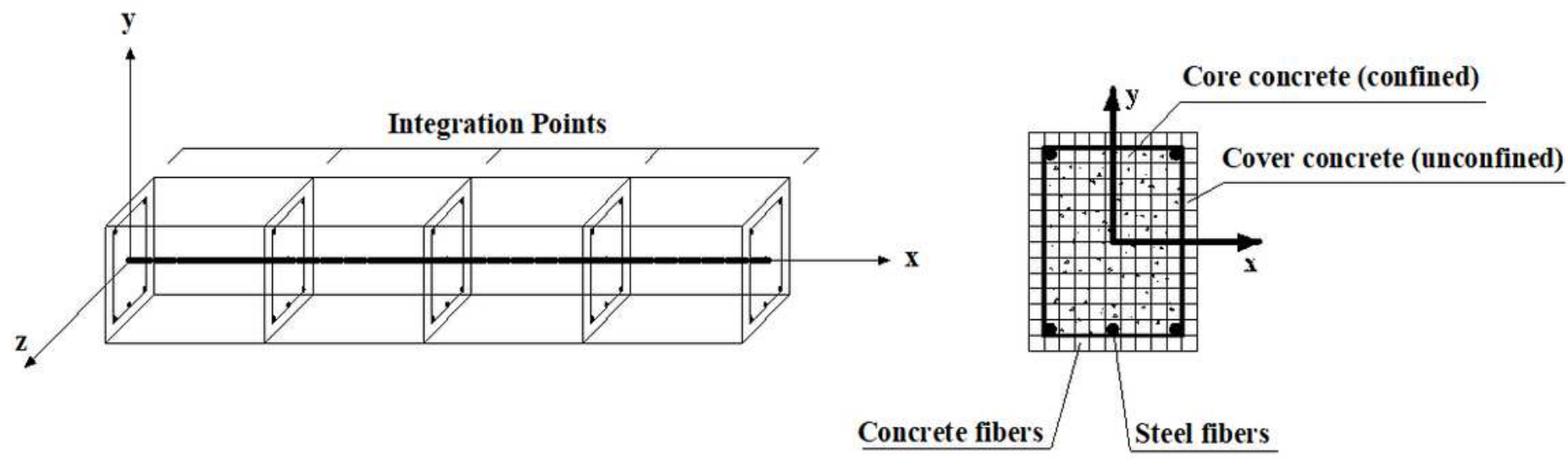

\section{Figure 1}

The fiber beam-column element and discretization of the cross-section (Seismosoft, 2016)

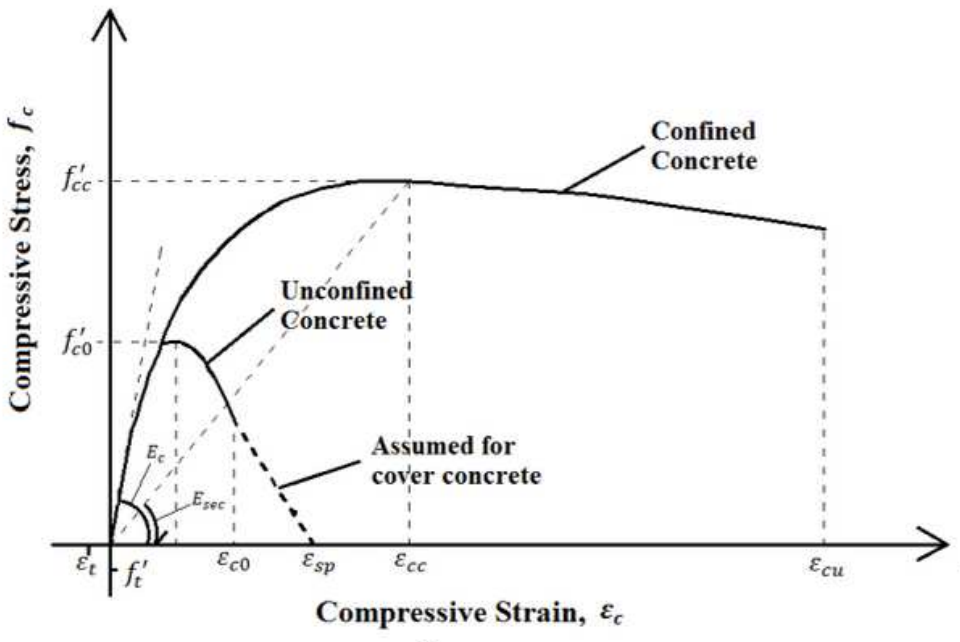

a)

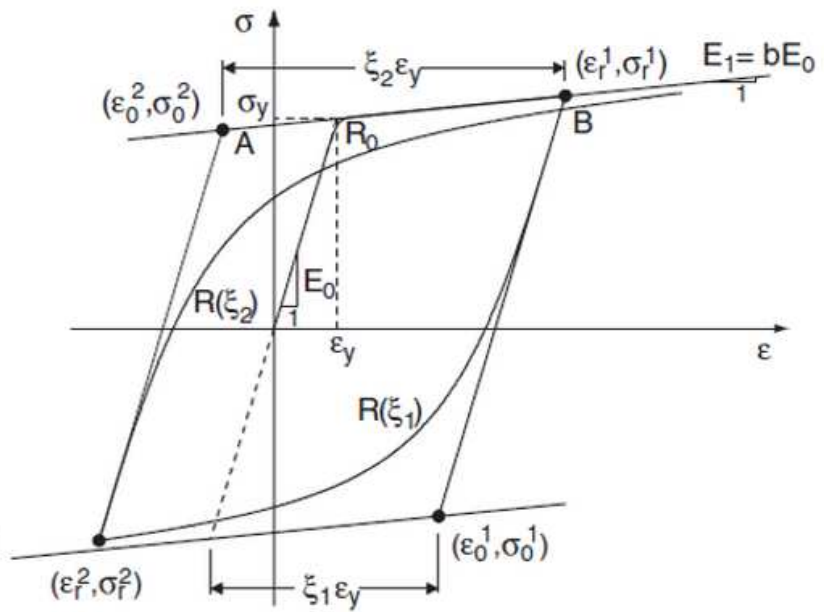

b)

\section{Figure 2}

a) Mander-Priestley-Park concrete model (Mander et al., 1988) and b) Modified Menegotto and Pinto steel model (Kolozvari et al., 2015). 


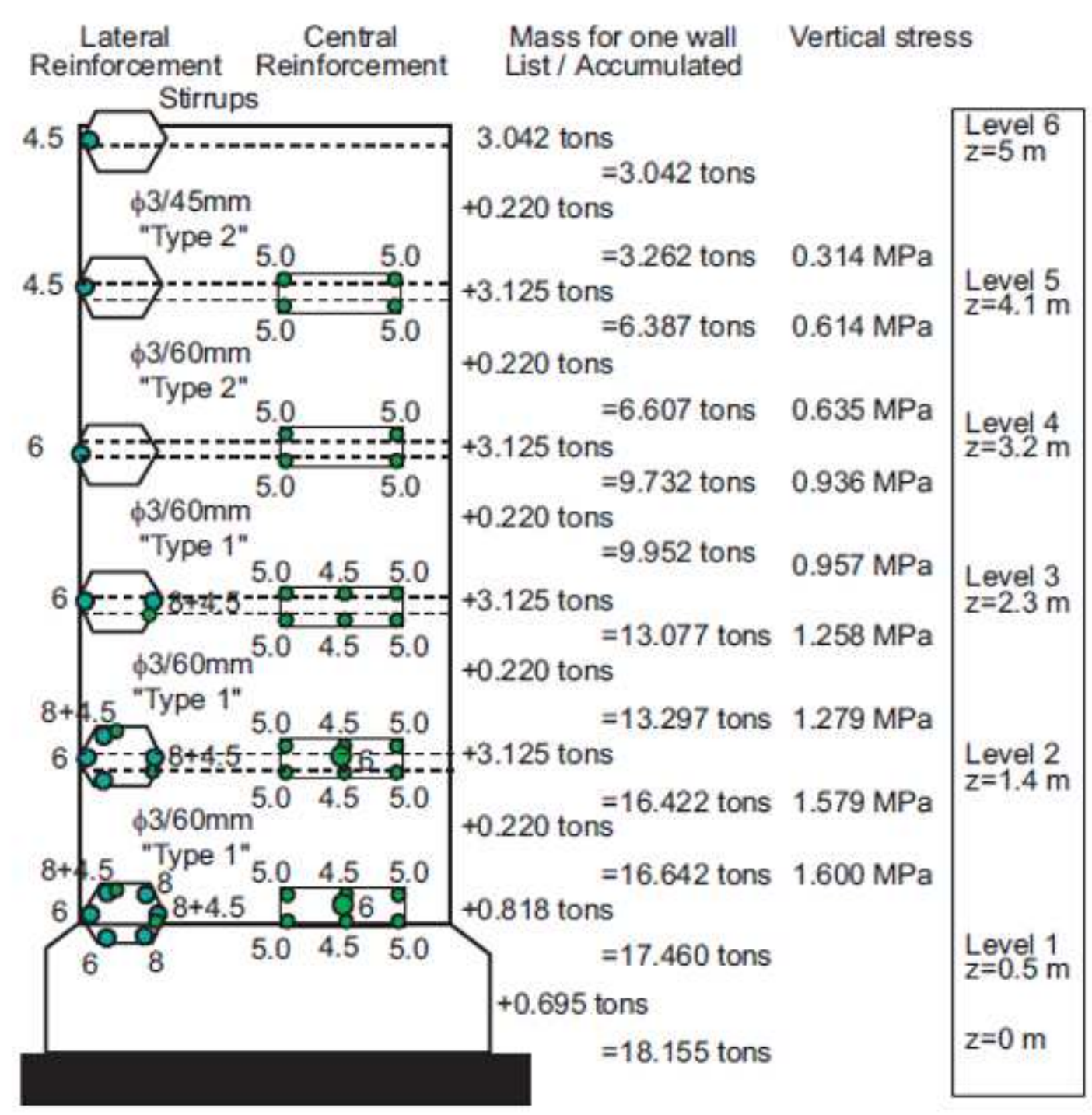

Figure 3

Steel reinforcement and mass details for one wall of the CAMUS I structure (Martinelli, 2007) 


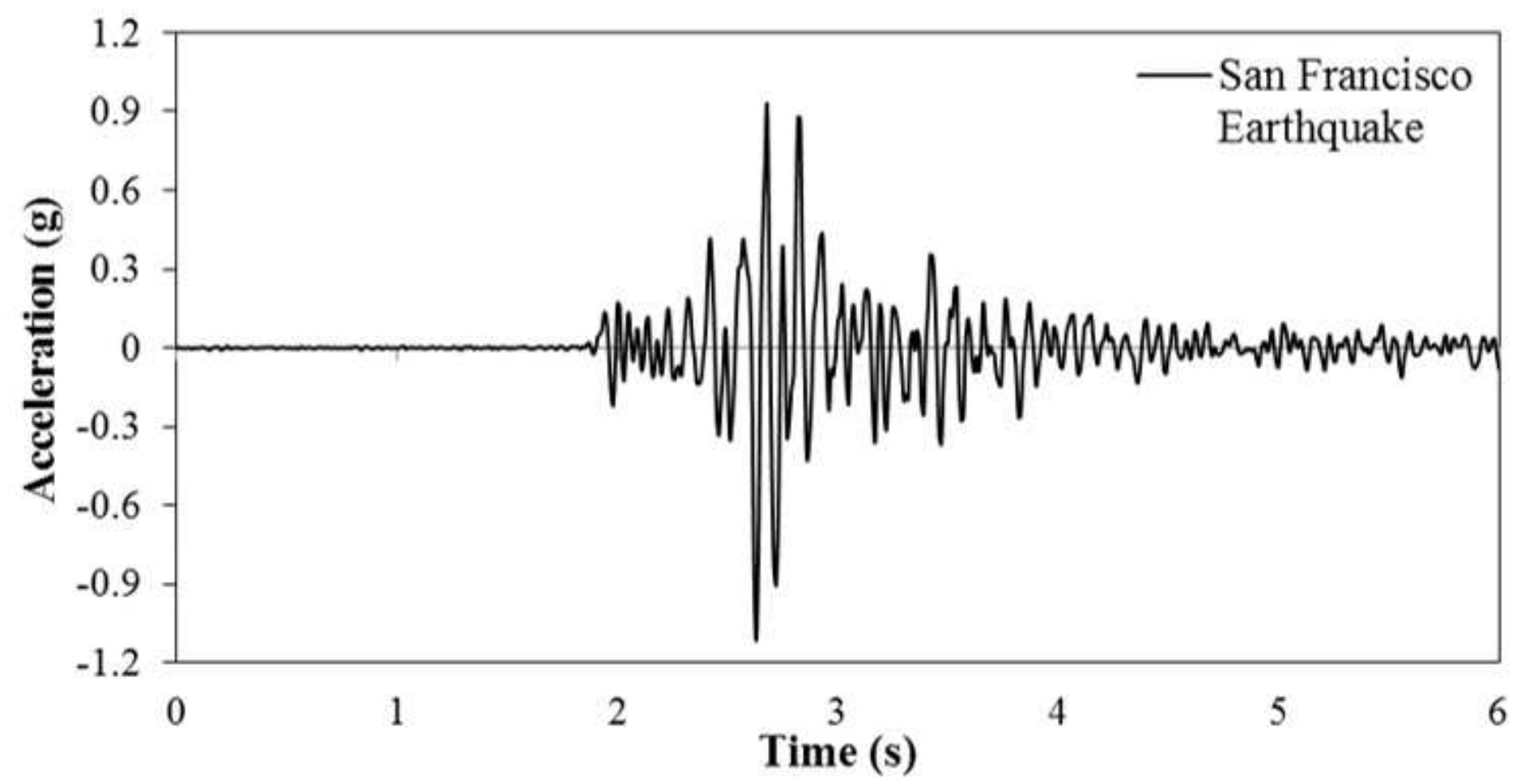

Figure 4

The scaled 1957 San Francisco earthquake loading (Kazaz et al., 2006) 

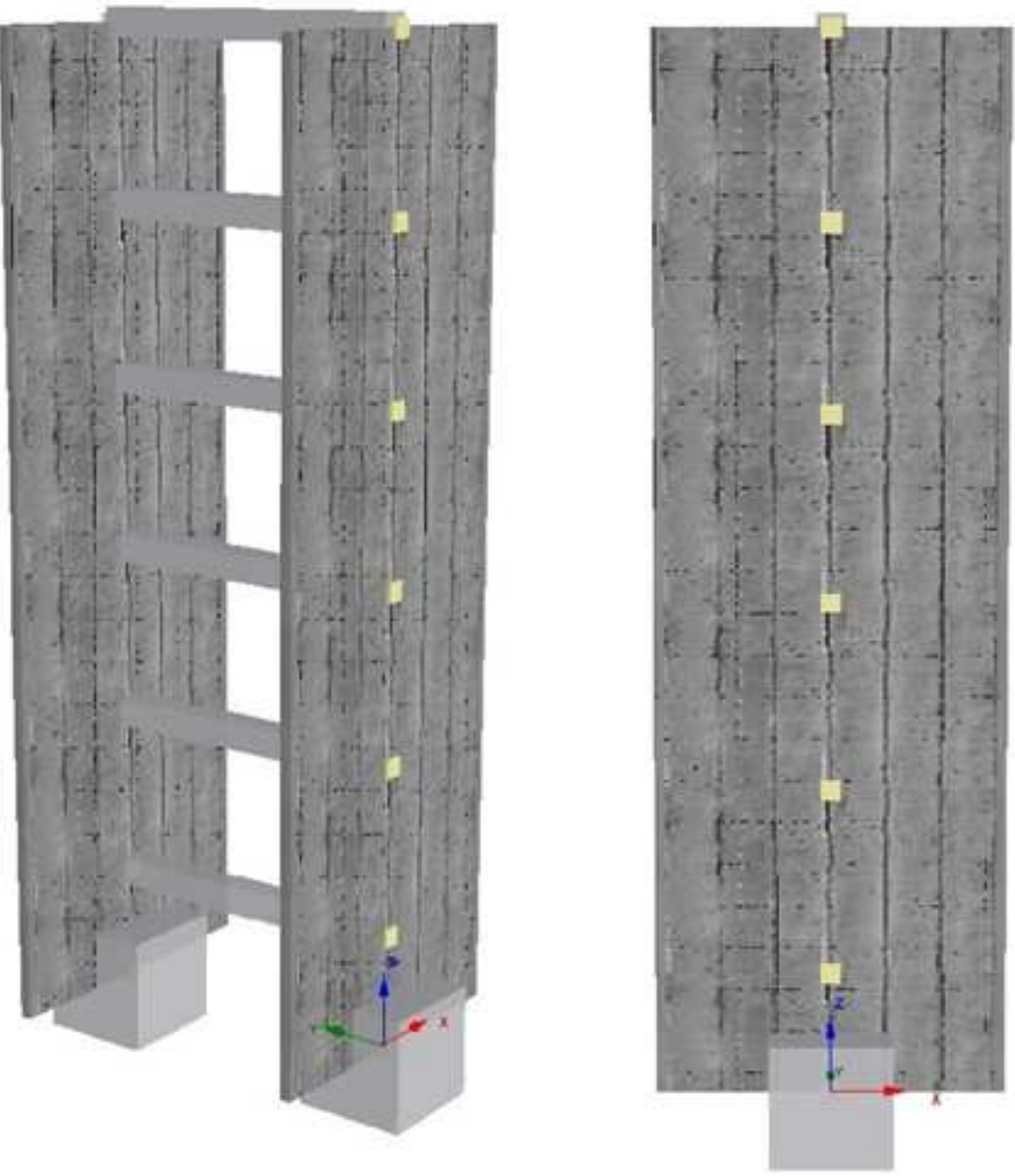

Lw

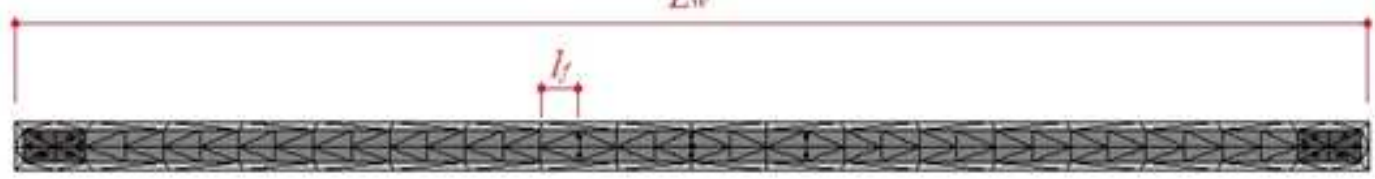

Figure 5

$3 \mathrm{D}$ view of the CAMUS I structure model and meshing of the shear wall 


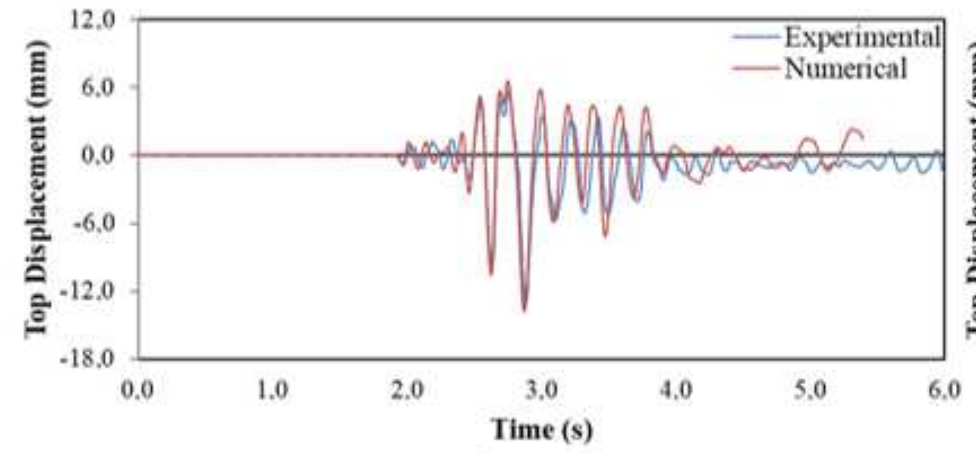

a) SPD

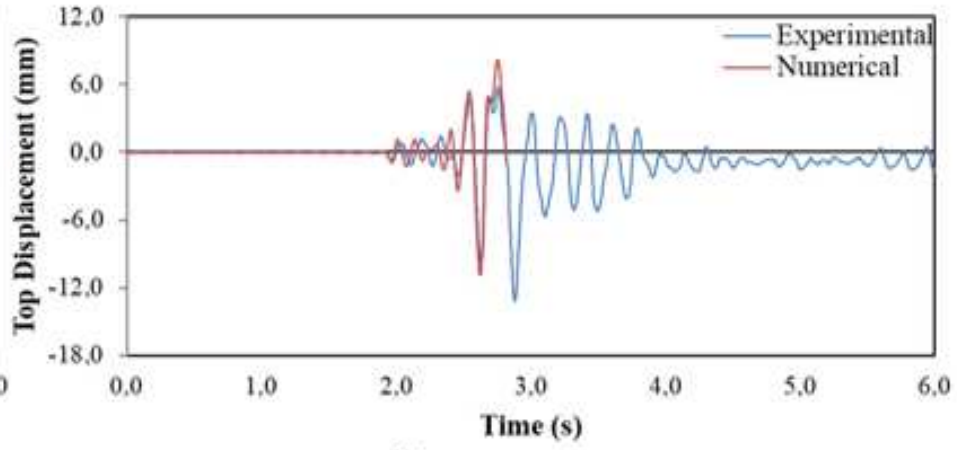

b) MPD

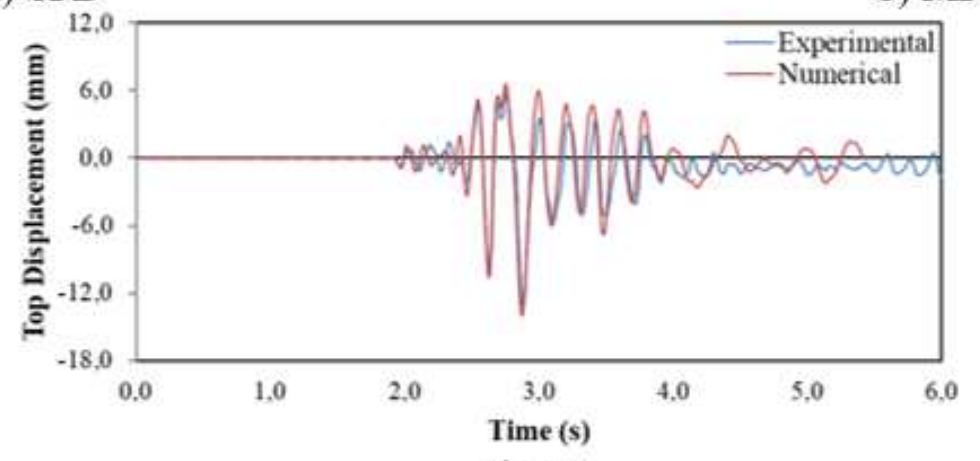

c) $\mathrm{RD}$

Figure 6

Top displacement responses of the CAMUS I for the damping ratio of $2 \%$

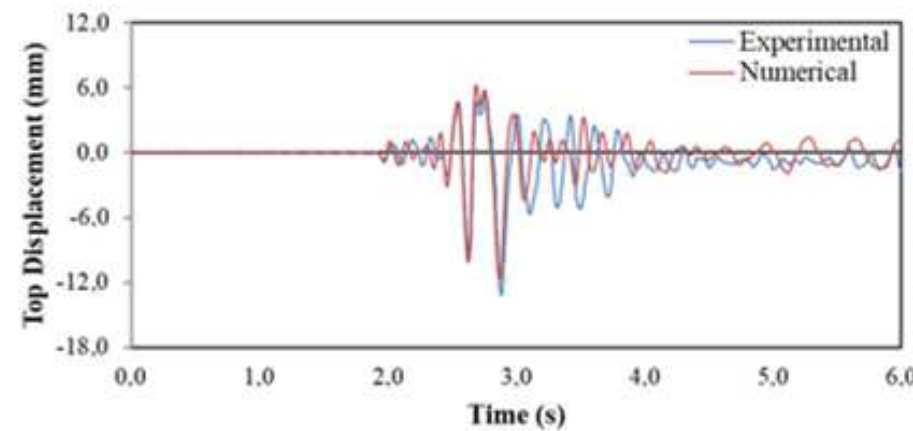

a) $\mathrm{SPD}$

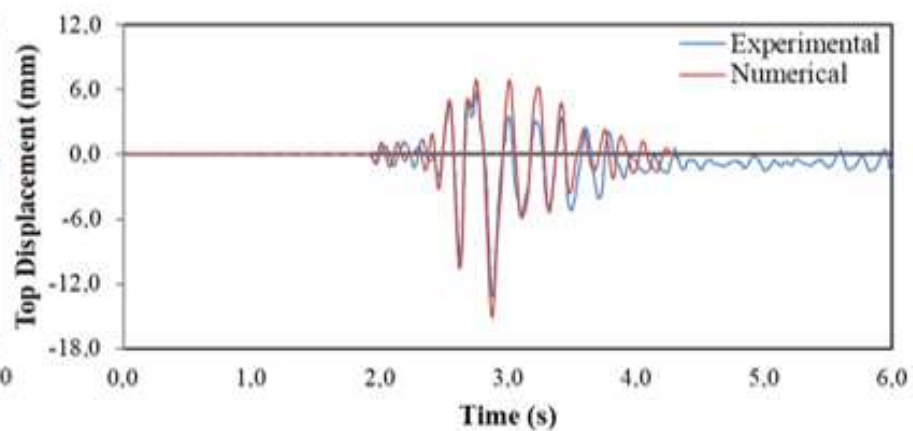

b) MPD

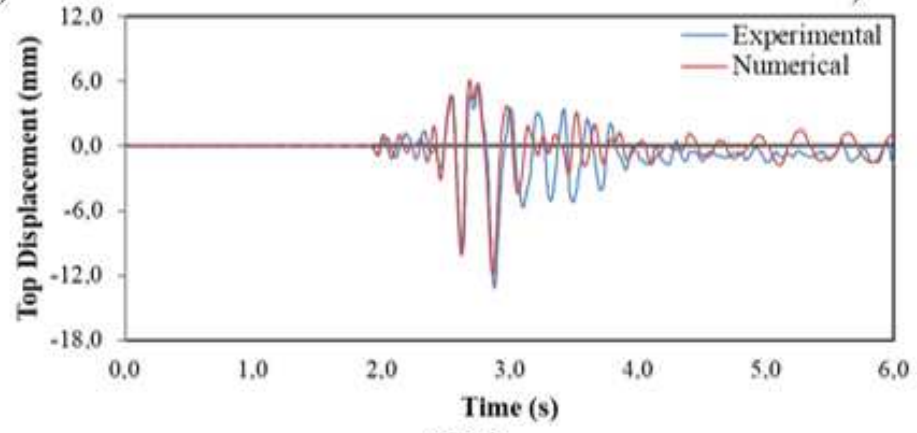

c) $\mathrm{RD}$

\section{Figure 7}

Top displacement responses of the CAMUS I for the damping ratio of $3 \%$ 


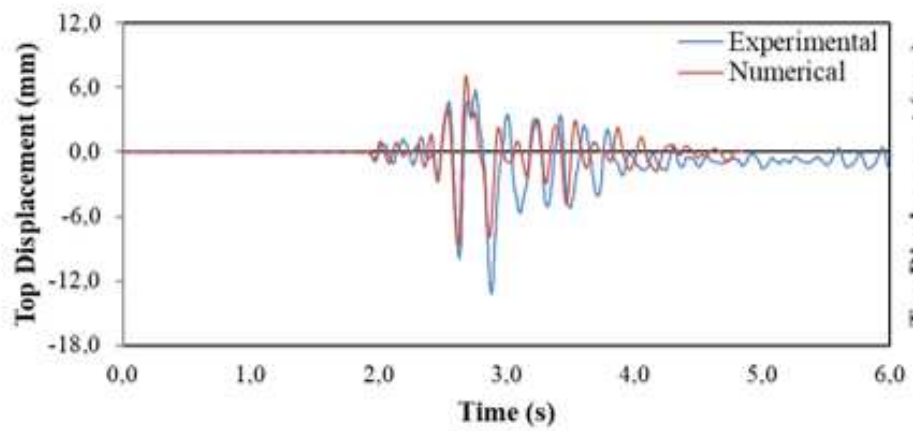

a) SPD

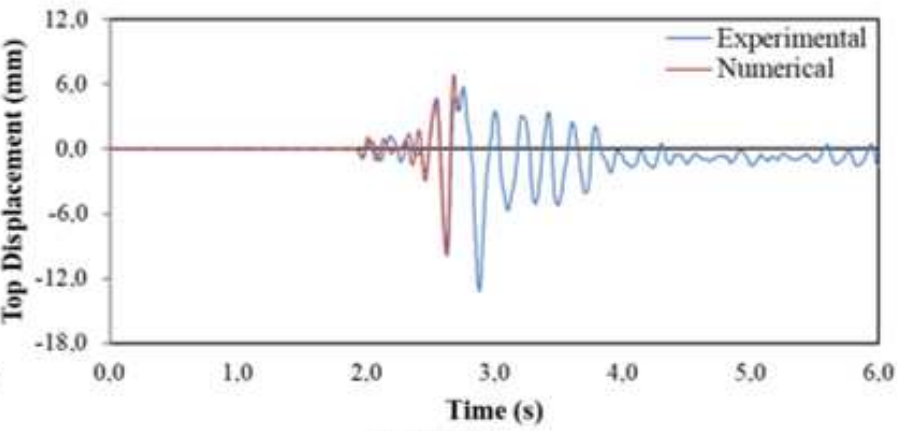

b) MPD

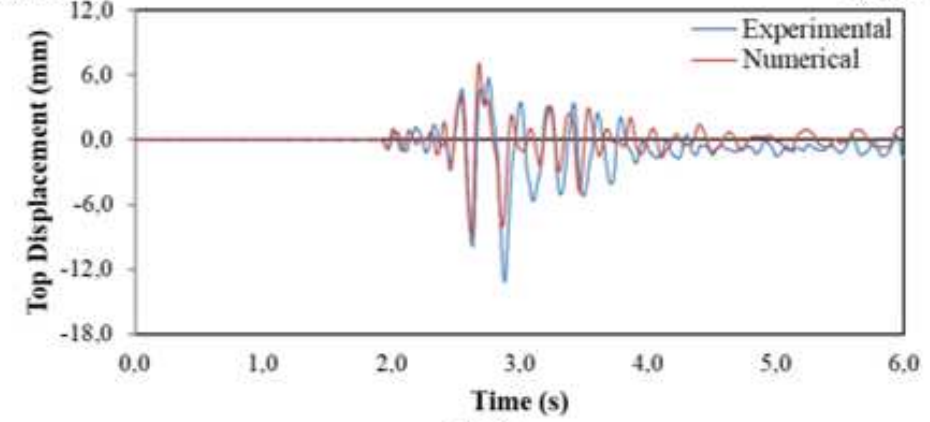

c) $\mathrm{RD}$

\section{Figure 8}

Top displacement responses of the CAMUS I for the damping ratio of $5 \%$

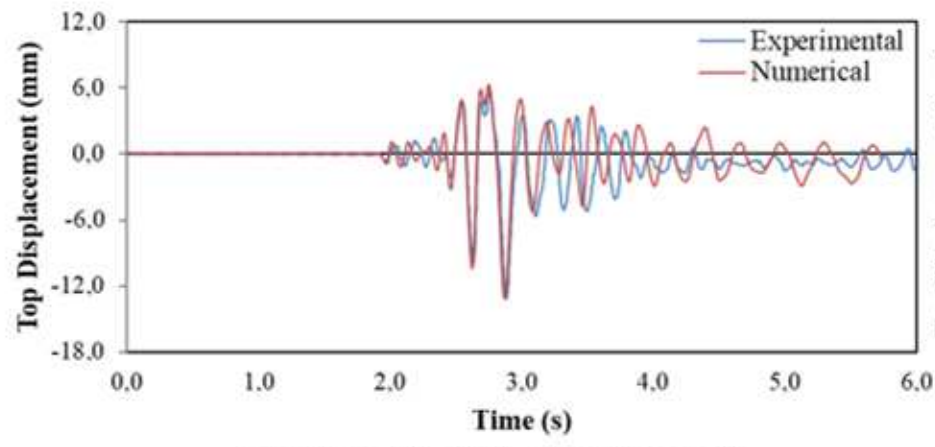

a) SPD at $2.49 \%$ damping ratio

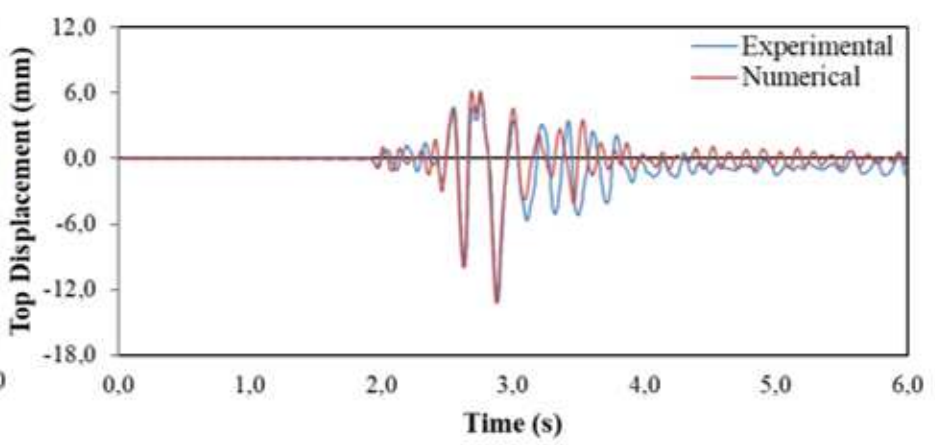

b) MPD at $4.52 \%$ damping ratio

\section{Figure 9}

Top displacement responses of the CAMUS I for SPD and MPD types at the optimum damping ratios 


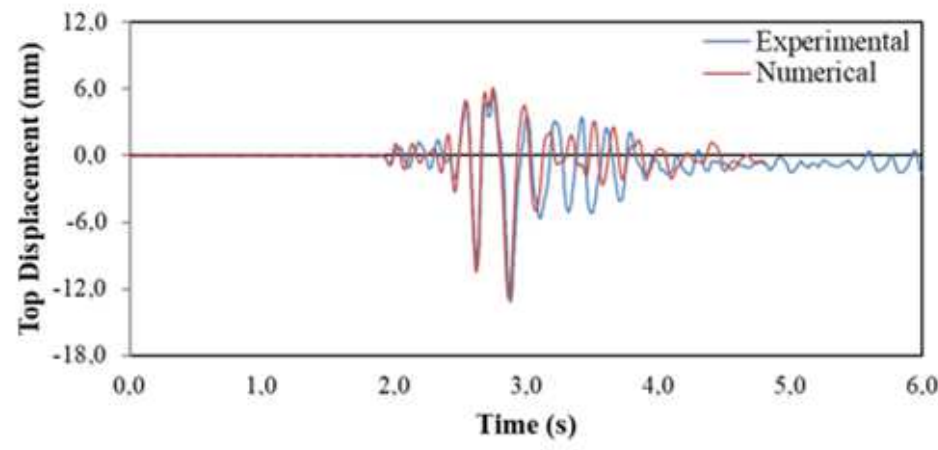

a) $2.49-4.52 \%$ damping ratios

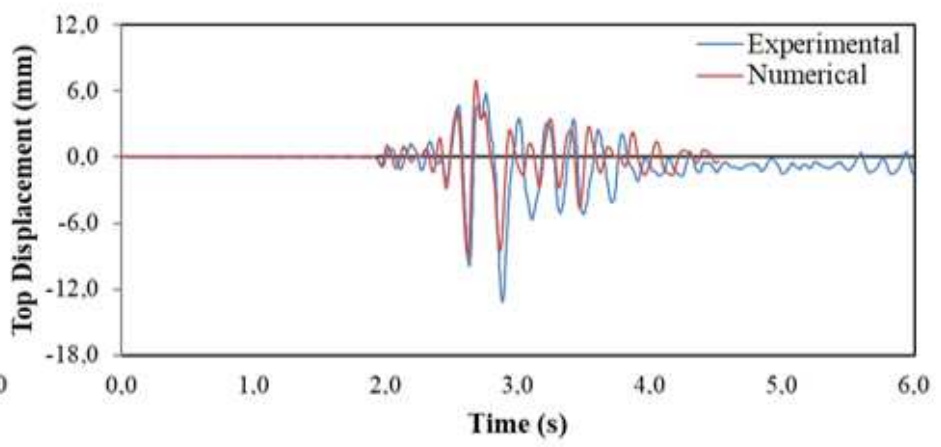

b) $4.52-2.49 \%$ damping ratios

Figure 10

Top displacement responses of the CAMUS I for RD at the optimum damping ratios of the first two effective modes

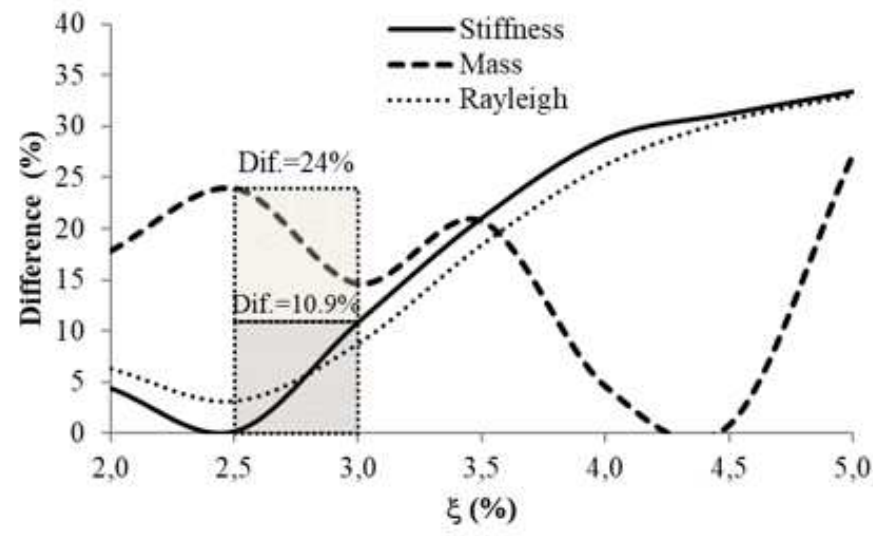

a) top displacement

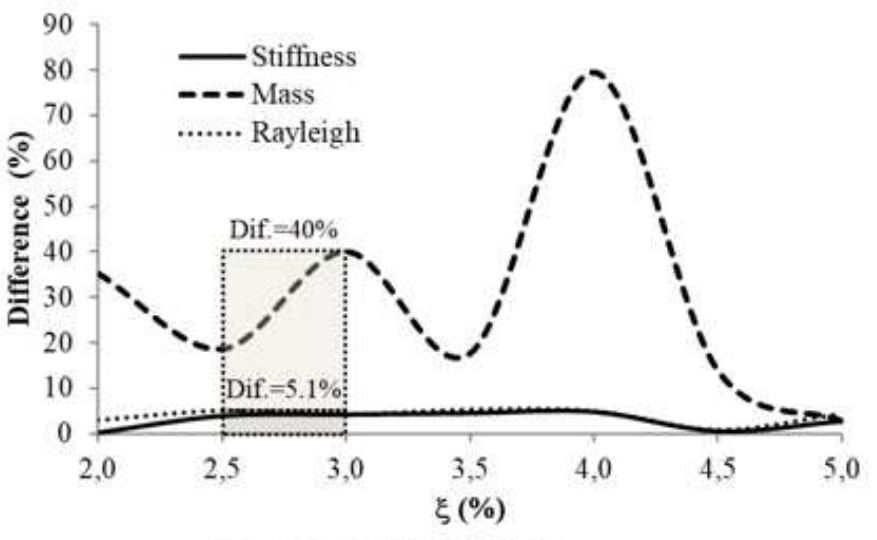

b) base shear force

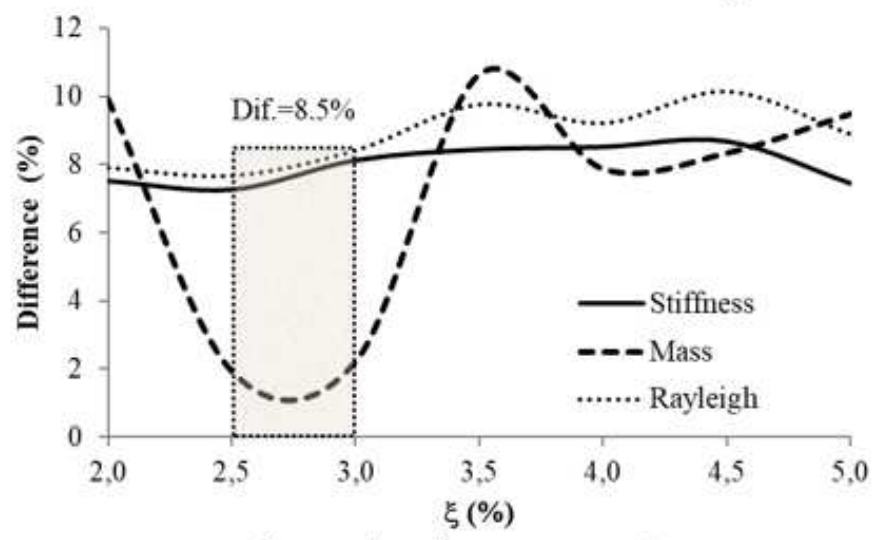

c) overturning moment

Figure 11

Comparisons of absolute maximum values obtained by numerical analysis with experimental results of the CAMUS I structure for various damping types 

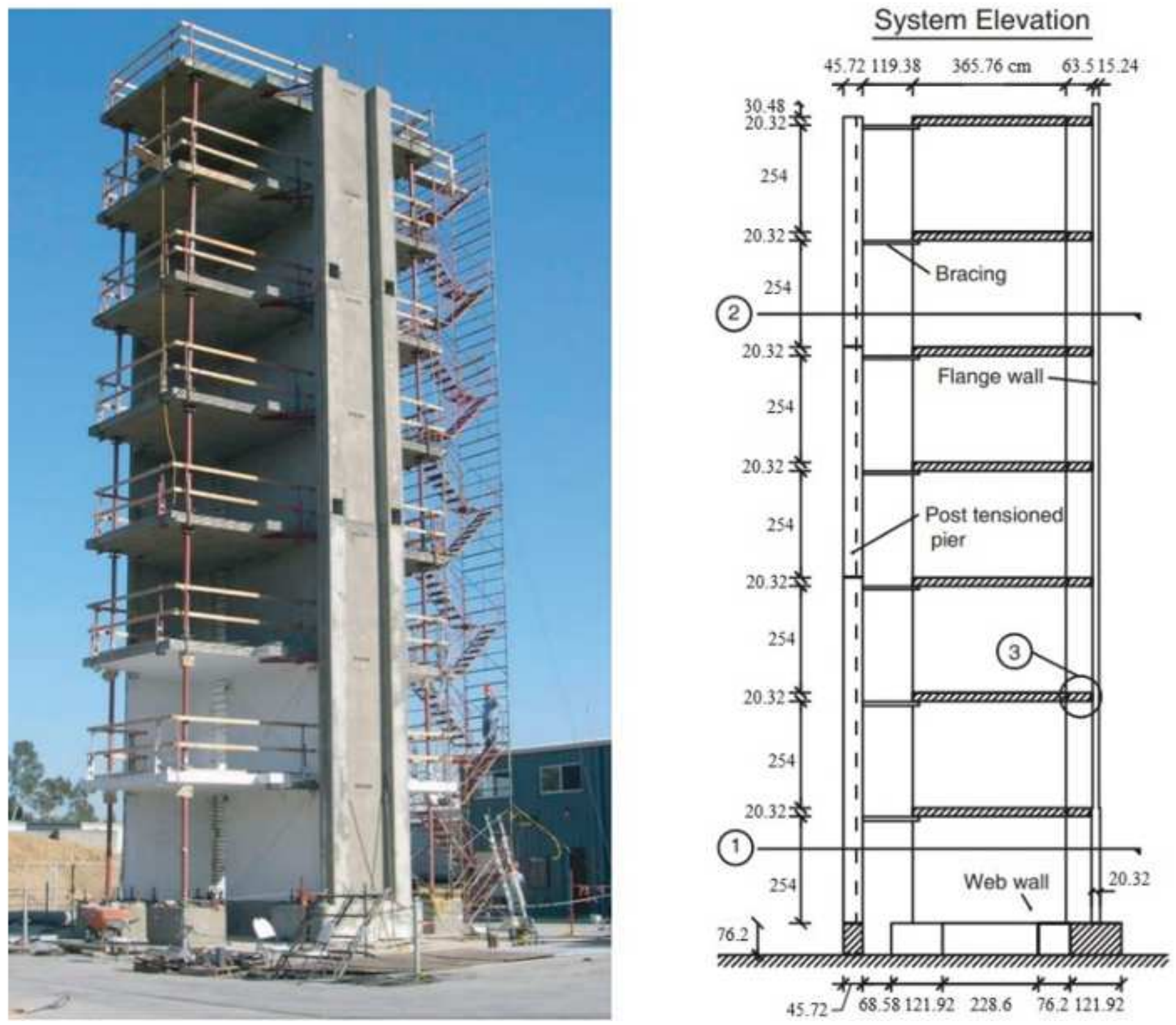

Figure 12

NEES-UCSD structure (Martinelli, 2007) 


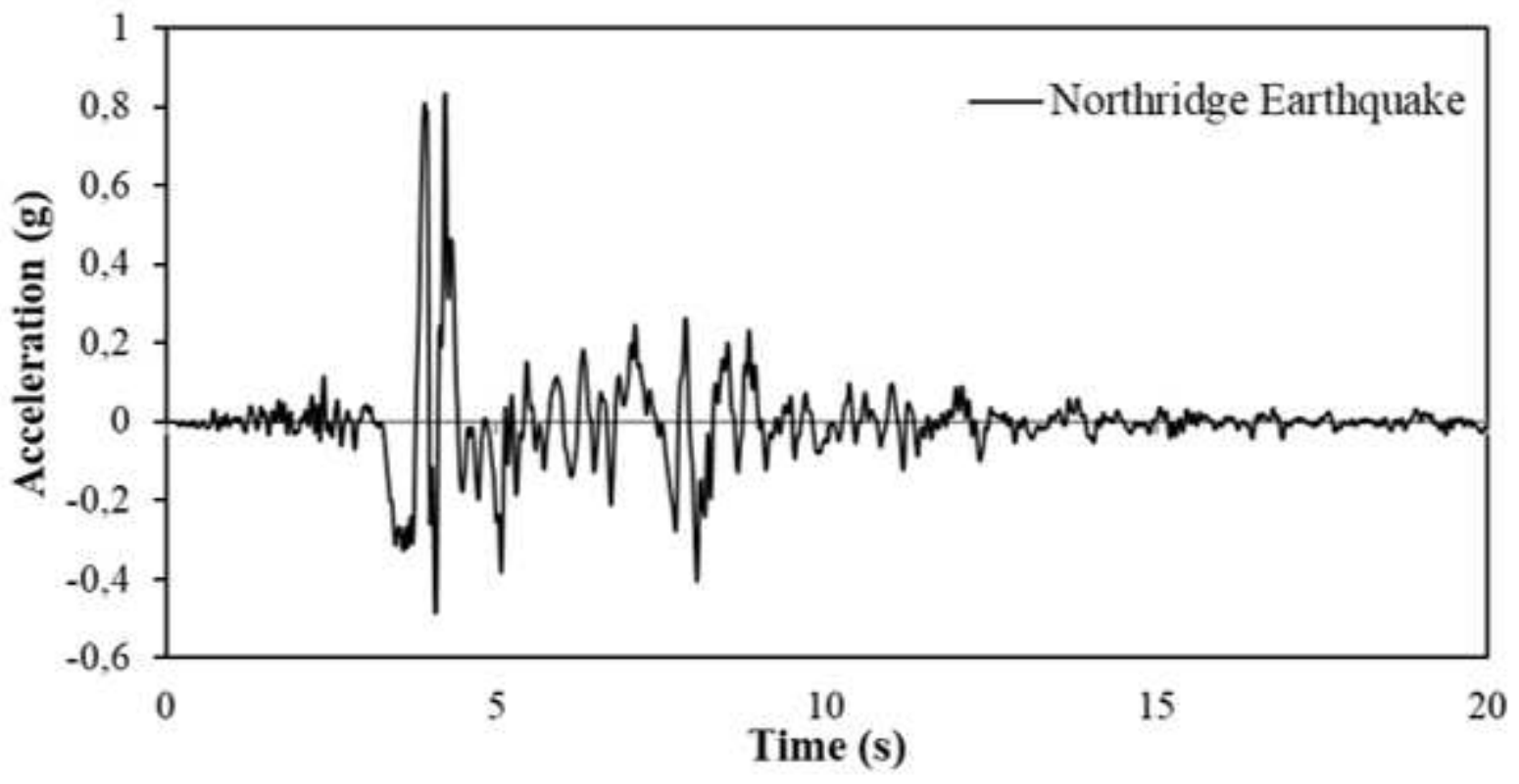

Figure 13

The acceleration record of the 1994 Northridge earthquake (Seismosoft, 2016)

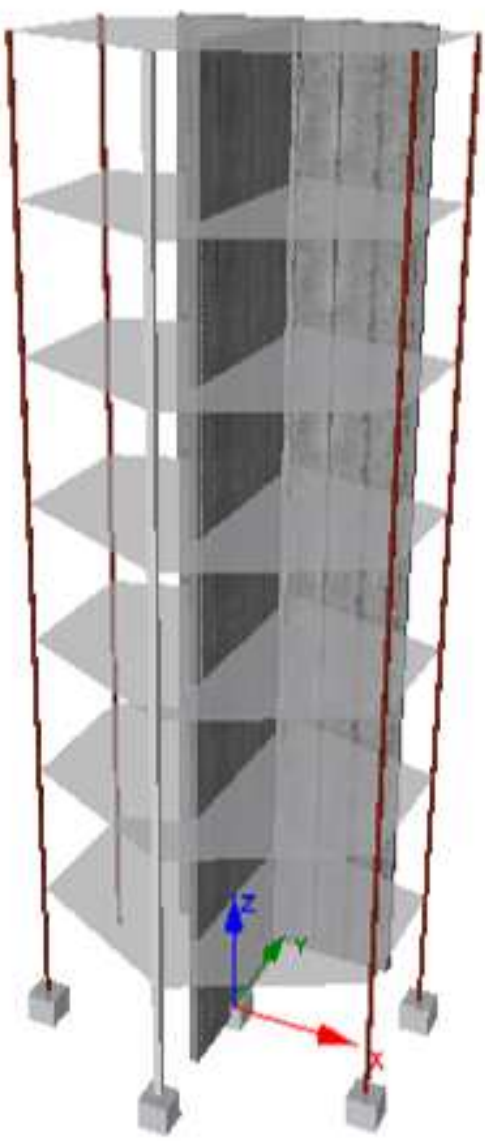

Figure 14

3D view of the NEES-UCSD structure model 


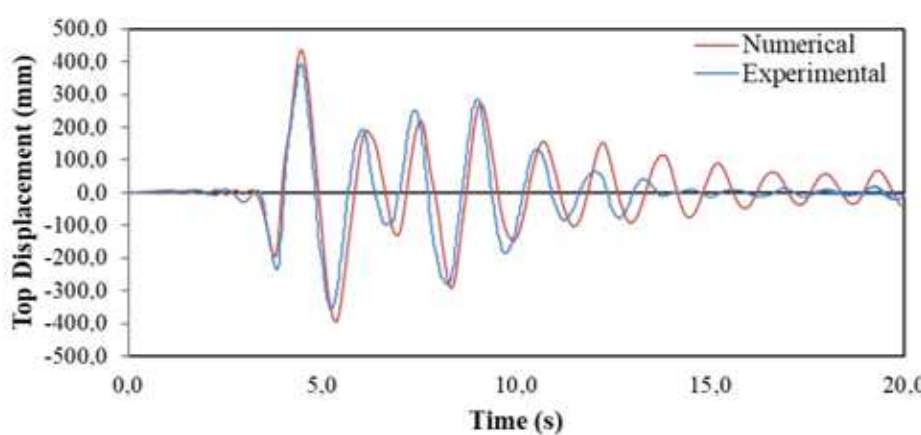

a) $\mathrm{SPD}$

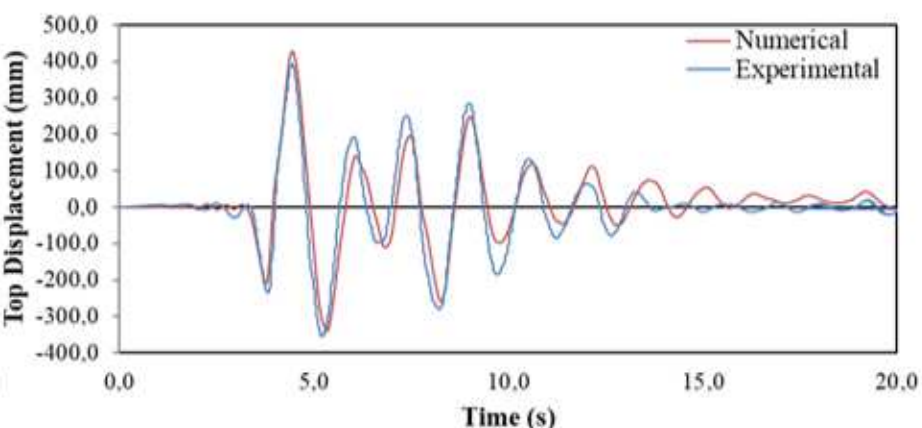

b) MPD

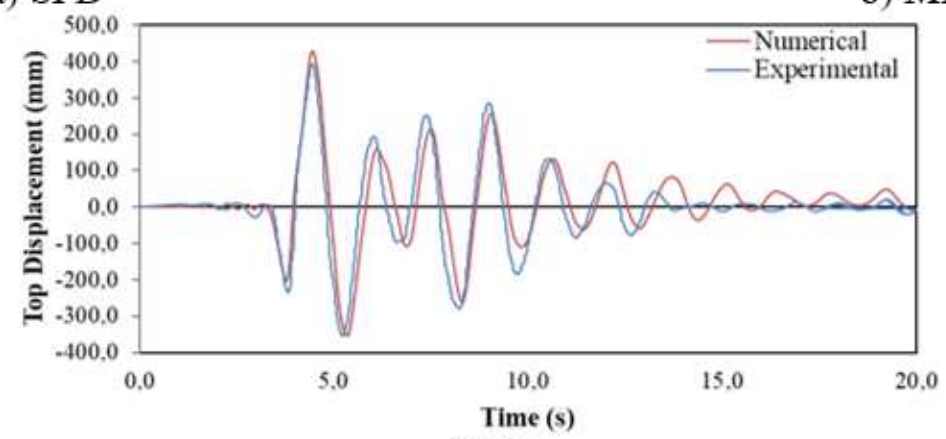

c) $\mathrm{RD}$

\section{Figure 15}

Top displacement responses of the CAMUS I for the damping ratio of $2 \%$

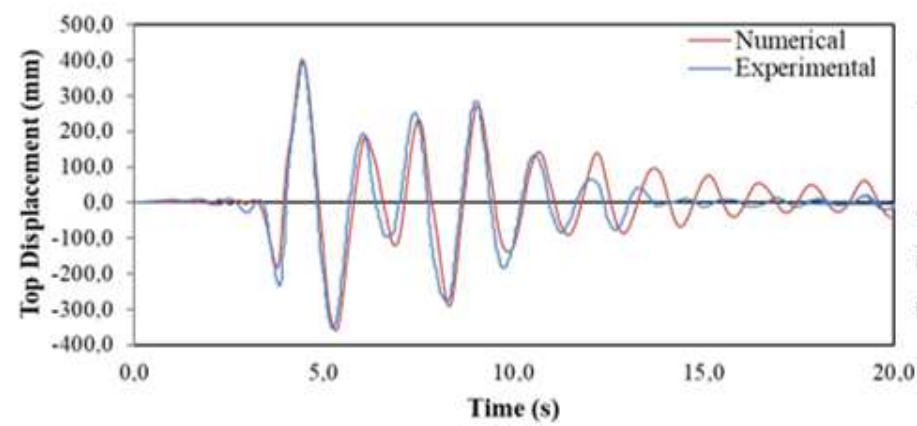

a) SPD

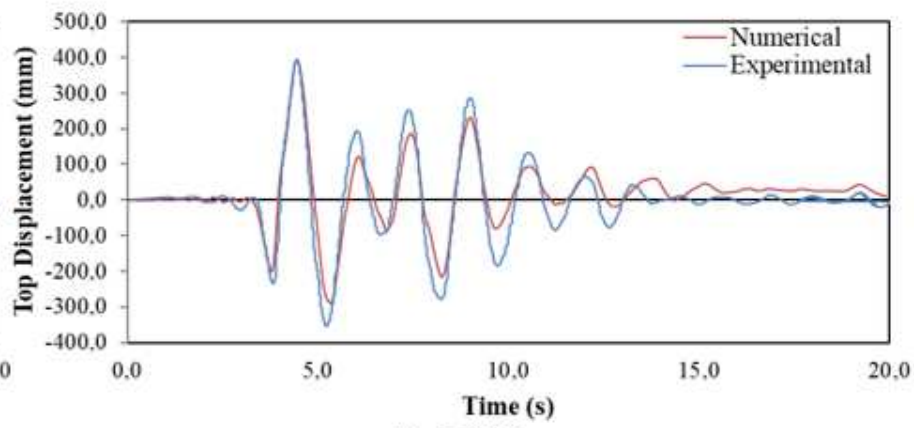

b) MPD

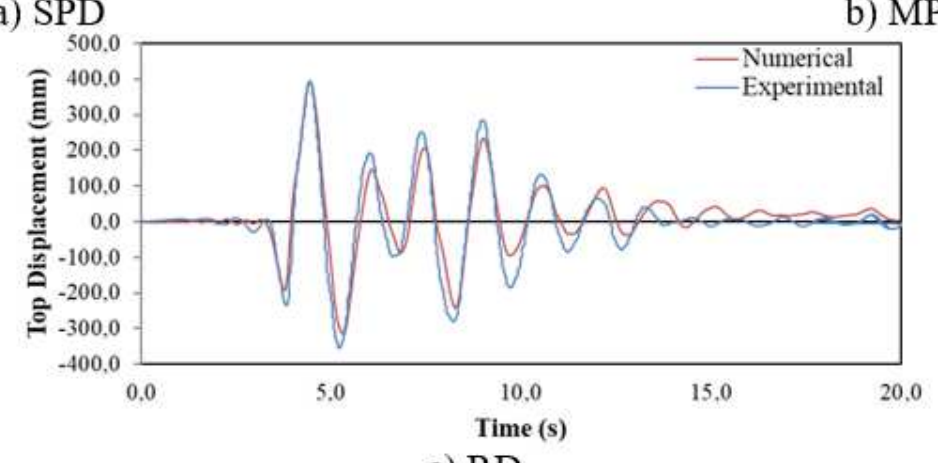

c) $\mathrm{RD}$

Figure 16

Top displacement responses of the CAMUS I for the damping ratio of $3 \%$ 


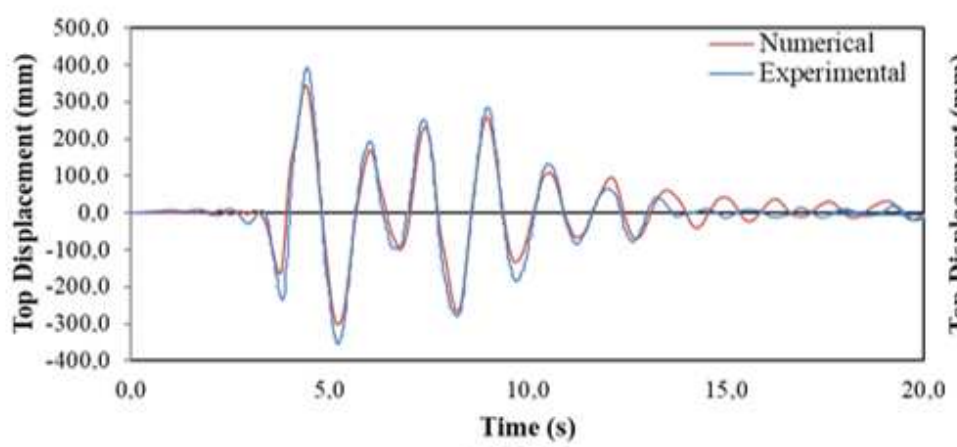

a) SPD

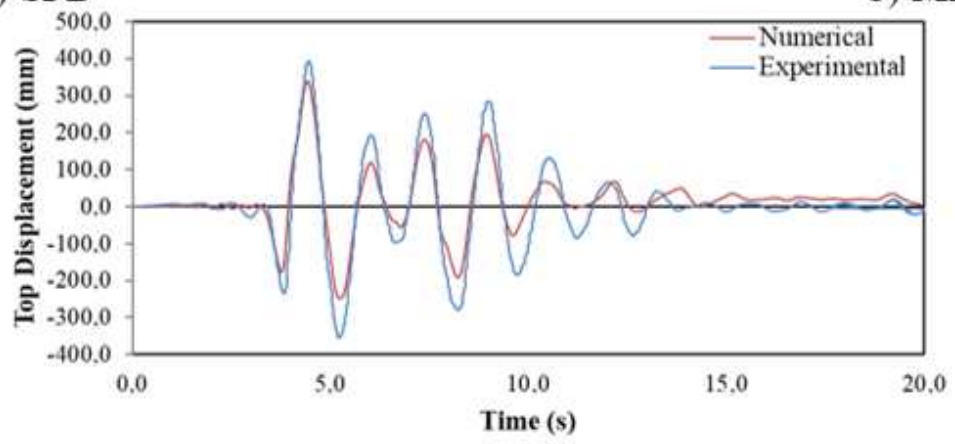

c) $\mathrm{RD}$

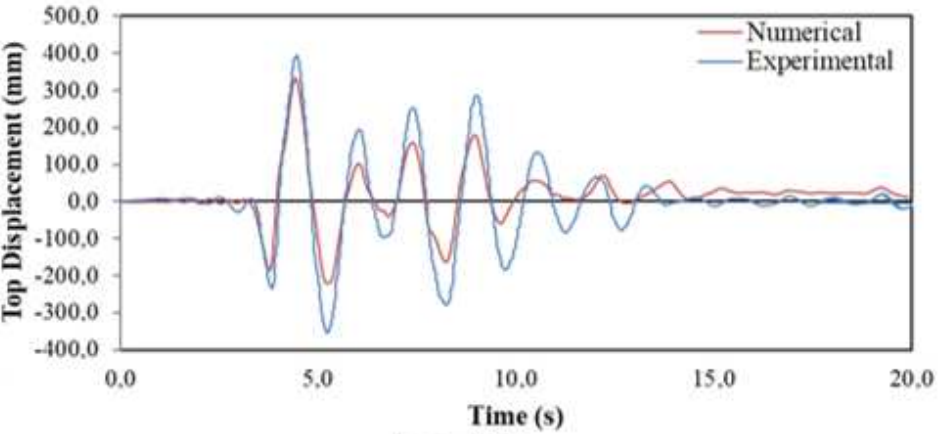

b) MPD

\section{Figure 17}

Top displacement responses of the CAMUS I for the damping ratio of $5 \%$

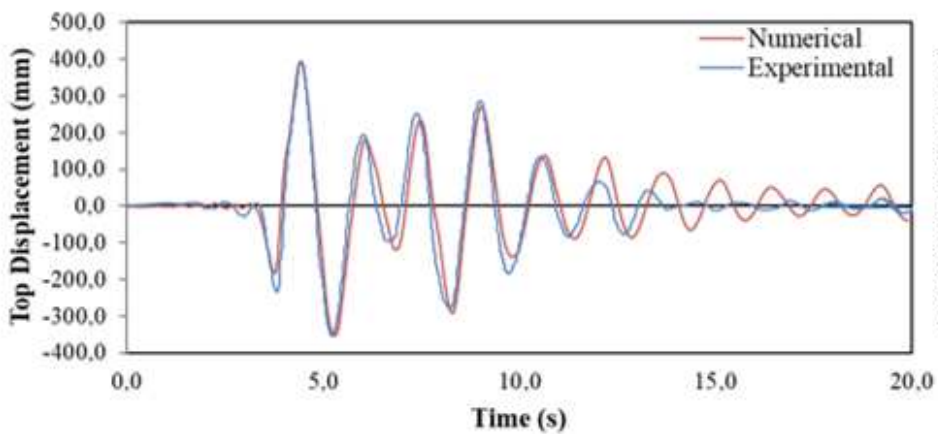

a) $\mathrm{SPD}$ at $3.25 \%$ damping ratio

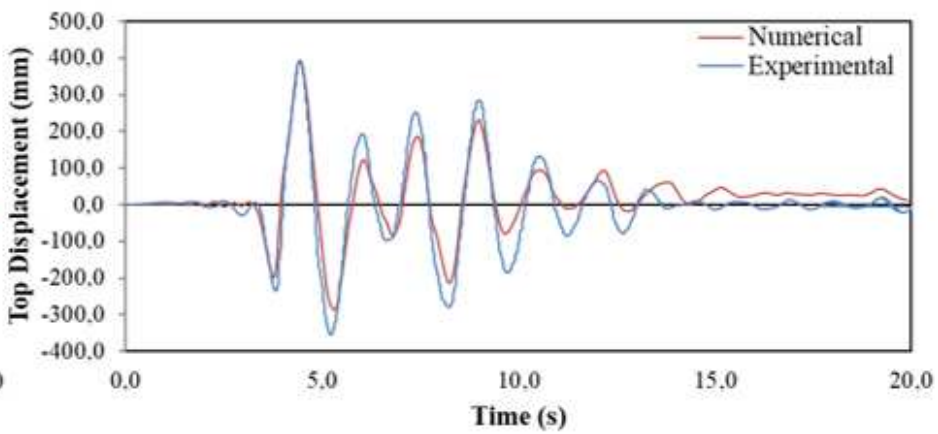

b) MPD at $3.00 \%$ damping ratio

\section{Figure 18}

Top displacement responses of the NEES-UCSD for SPD and MPD types at optimum damping ratios

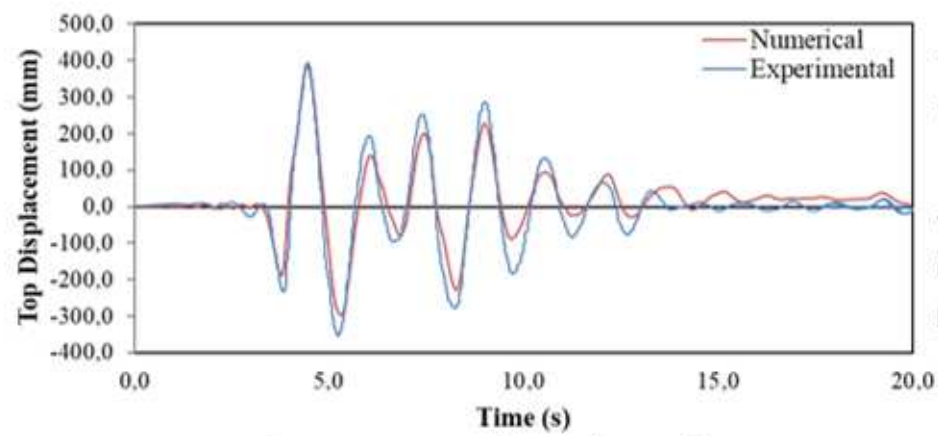

a) $3.25-3.00 \%$ damping ratios

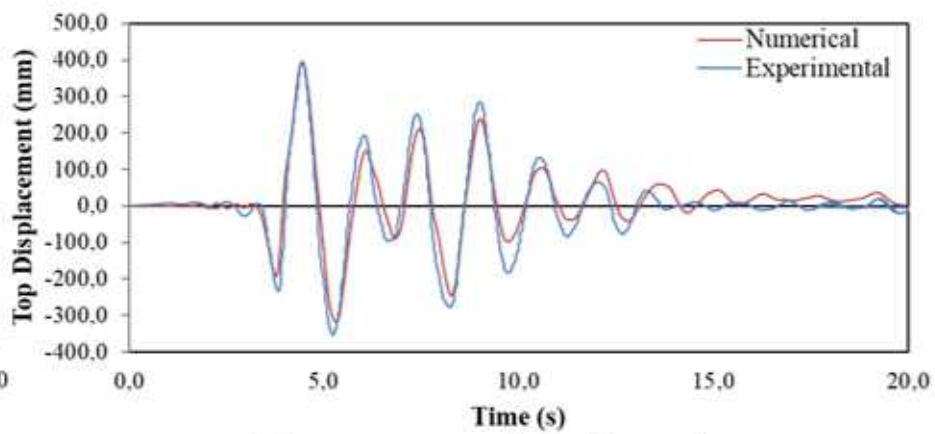

b) $3.00-3.25 \%$ damping ratios 
Figure 19

Top displacement responses of the NEES-UCSD for RD type at the optimum damping ratios of the first two effective modes

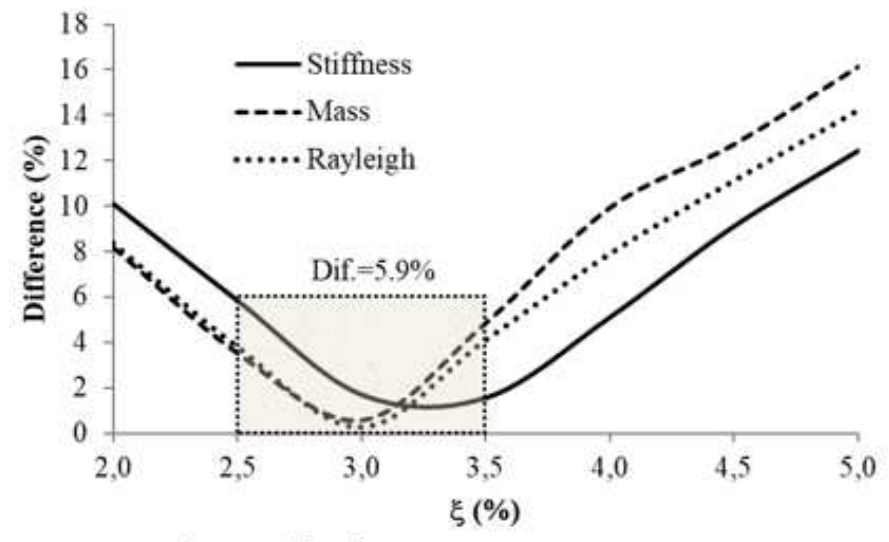

a) top displacement

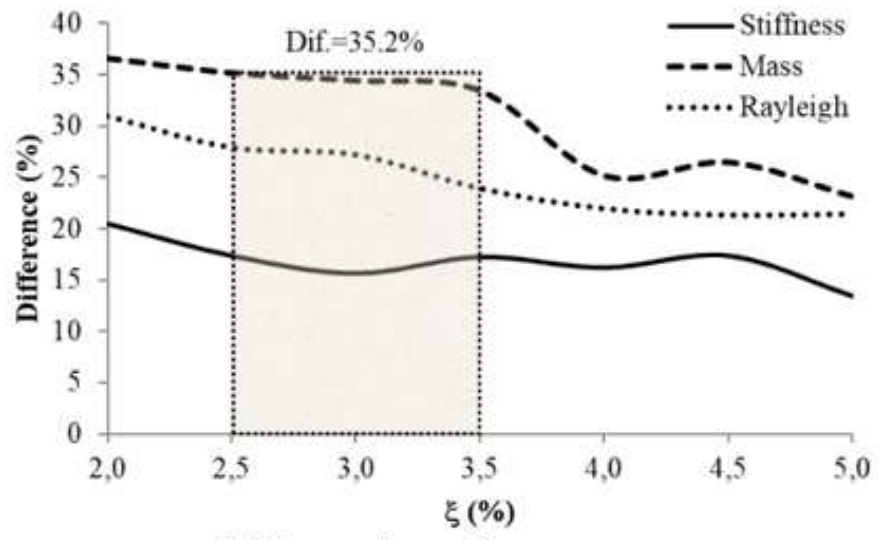

b) base shear force

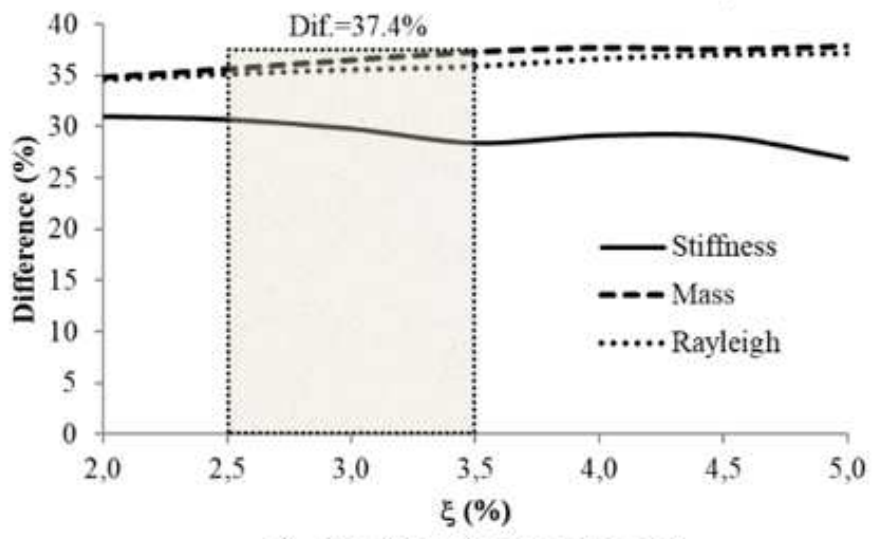

c) overturning moment

\section{Figure 20}

Comparisons of absolute maximum values obtained by numerical analysis with experimental results of the NEES-UCSD structure for various damping types 


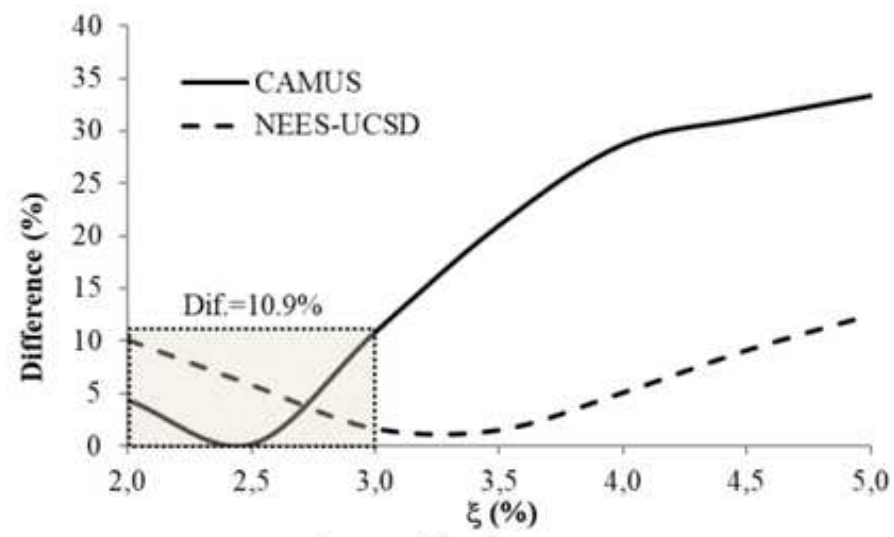

a) top displacement

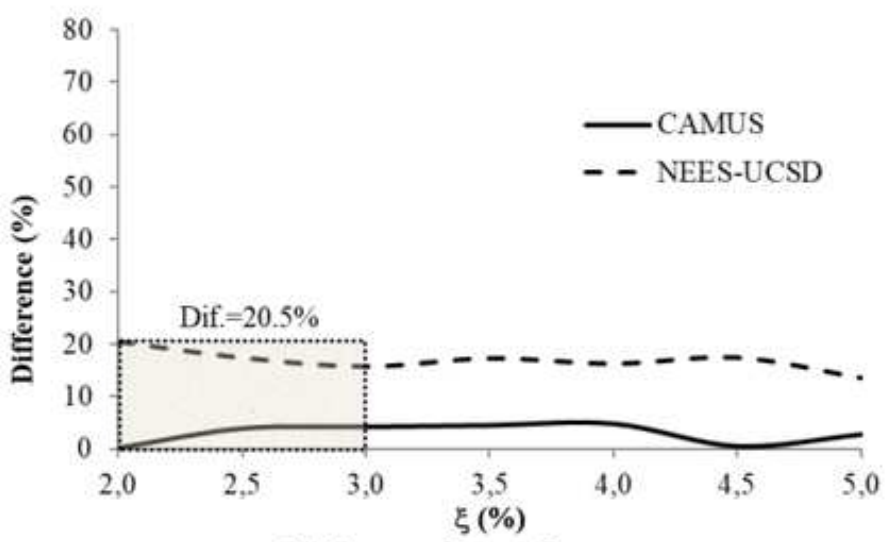

b) base shear force

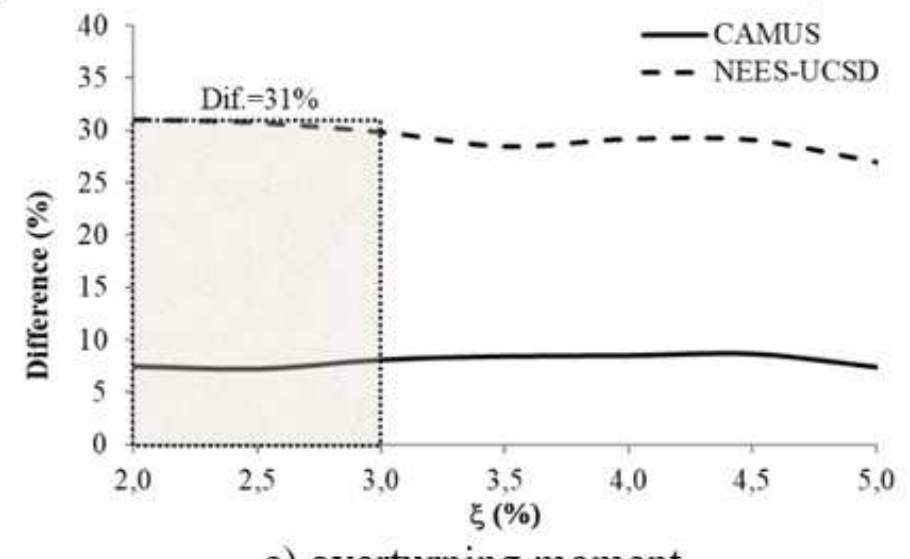

c) overturning moment

\section{Figure 21}

Comparisons of absolute maximum values obtained by numerical analysis with experimental results of the both shear wall structures for SPD 


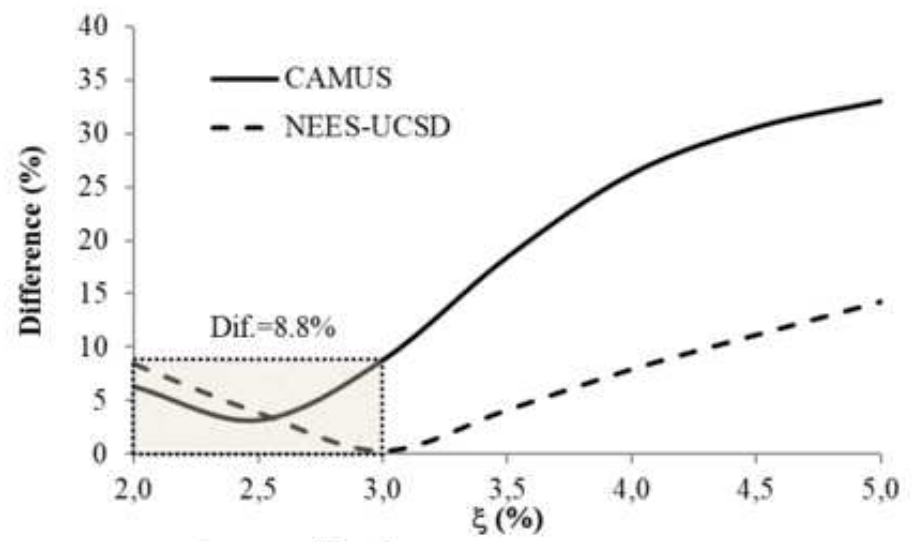

a) top displacement

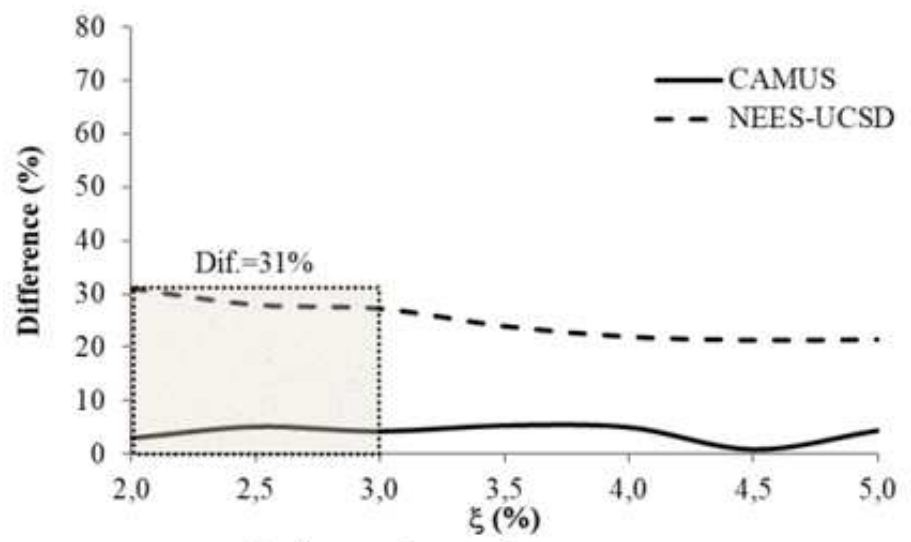

b) base shear force

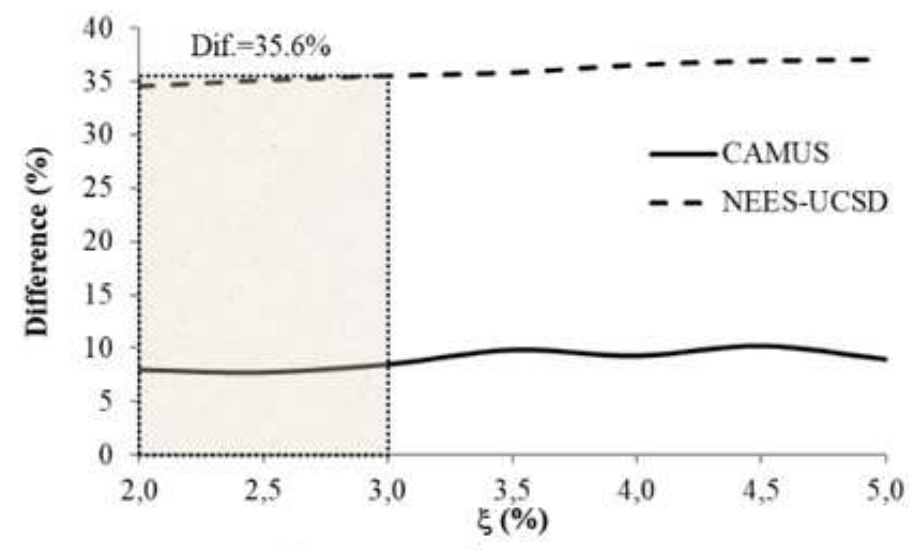

c) overturning moment

Figure 22

Comparisons of absolute maximum values obtained by numerical analysis with experimental results of the both shear wall structures for RD 


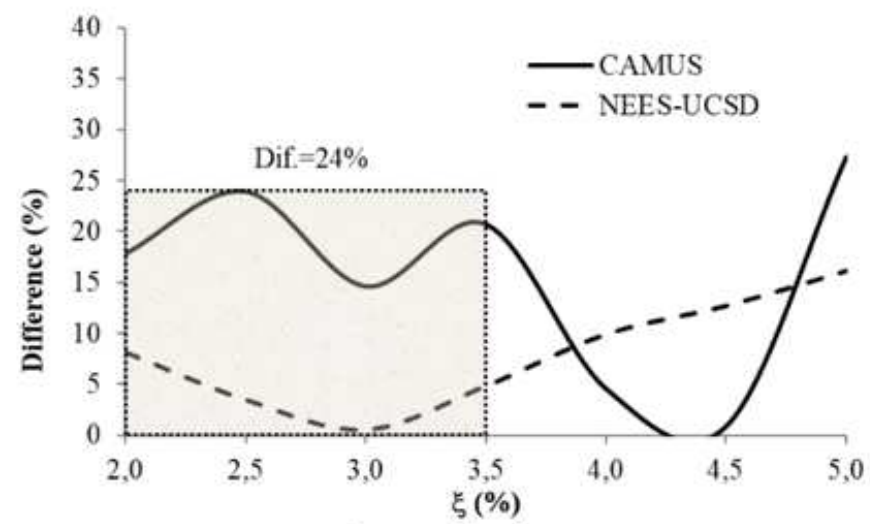

a) top displacement

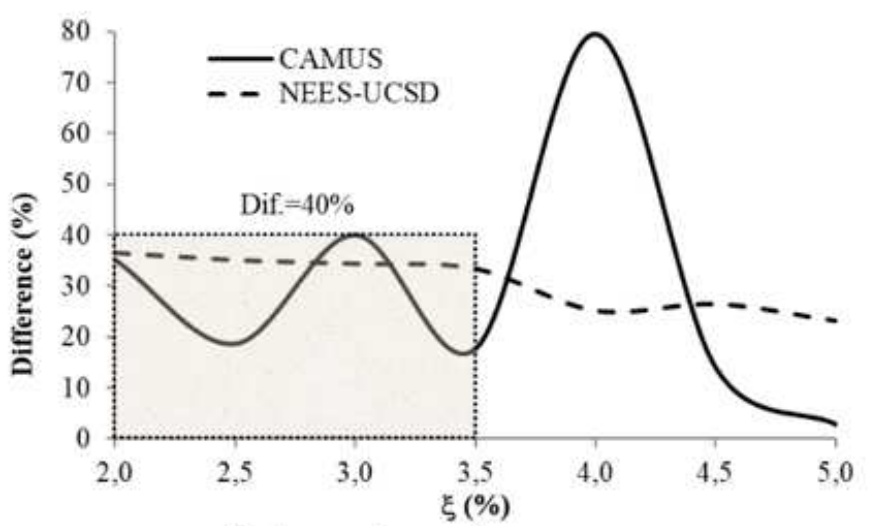

b) base shear force

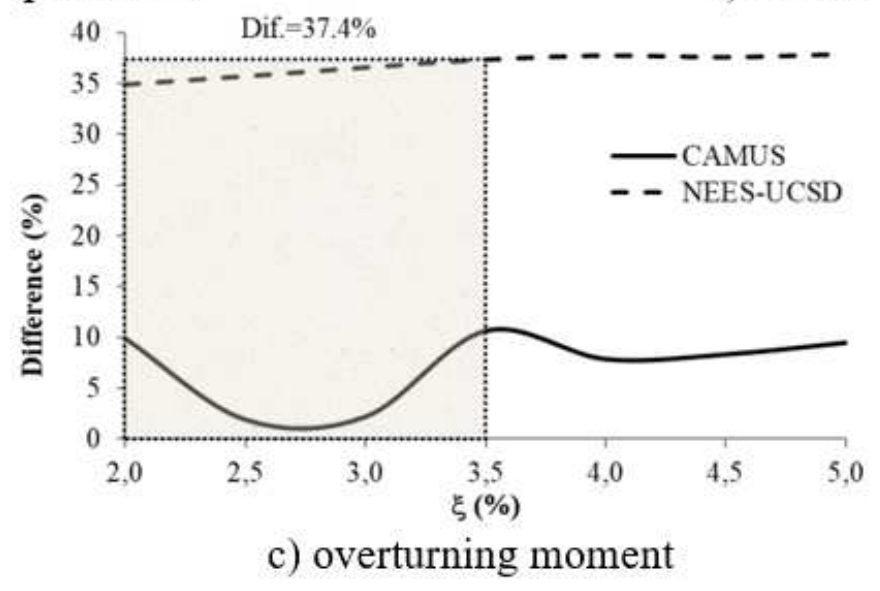

Figure 23

Comparisons of absolute maximum values obtained by numerical analysis with experimental results of the both shear wall structures for MPD 